\title{
TMC1 MODELS
}

Sanket Walujkar ${ }^{1,2} *$, Jeffrey M. Lotthammer ${ }^{1}$, Collin R. Nisler ${ }^{1,3}$, Joseph C. Sudar $^{1}$, Angela Ballesteros ${ }^{4}$, 


\section{Abstract}

2 Inner-ear sensory hair cells convert mechanical stimuli from sound and head movements into electrical signals during 3 mechanotransduction. Identification of all molecular components of the inner-ear mechanotransduction apparatus is 4 ongoing; however, there is strong evidence that TMC1 and TMC2 are pore-forming subunits of the complex. We present 5 molecular dynamics simulations that probe ion conduction of TMC1 models built based on two different structures of 6 related TMEM16 proteins. Unlike most channels, the TMC1 models do not show a central pore. Instead, simulations of 7 these models in a membrane environment at various voltages reveal a peripheral permeation pathway that is exposed to 8 lipids and that shows cation permeation at rates comparable to those measured in hair cells. Furthermore, our analyses 9 suggest that TMC1 gating mechanisms involve protein conformational changes and tension-induced lipid-mediated pore 0 widening. These results provide insights into ion conduction and activation mechanisms of hair-cell mechanotransduction 1 channels essential for hearing and balance. 


\section{INTRODUCTION}

2 In mammalian hearing, pressure waves from sound are transmitted through the auditory canal to sensory hair cells

3 responsible for mediating auditory perception in the cochlea of the inner ear ${ }^{1-4}$. Similarly, in the vestibular system, forces

4 from head movements are conveyed to vestibular hair cells responsible for the sense of balance ${ }^{5,6}$. The hair-cell

5 mechanosensory organelle consists of a bundle of hair-like projections called stereocilia that are arranged in rows of

6 increasing height. Proteinaceous oblique tip links connect the tip of each stereocilium to the side of the taller stereocilium

7 neighbor ${ }^{7-9}$ and are tensioned when mechanical stimuli cause deflections of hair bundles towards their tallest stereocilia

8 row. This tension is then transferred to a mechanically activated transduction channel complex that facilitates an influx of

9 potassium ions, depolarizing the hair cell ${ }^{10}$. This process occurs over microsecond timescales and triggers rapid signaling

0 cascades responsible for auditory and balance perception ${ }^{11,12}$.

1 Determining the molecular identity of the inner-ear mechanotransduction channel has been difficult. There is an average 2 of about 10,000 hair cells in the vertebrate inner ear, which is orders of magnitude smaller than the number of receptors in 3 other sensory systems that have been better characterized ${ }^{13}$. Experiments also suggest that there are about two channels 4 per tip link, with about 50 to 200 tip links per hair cell ${ }^{14,15}$. This scarcity of protein makes the complex difficult to study 5 by traditional biochemical techniques ${ }^{16}$, explaining why the molecular identity of the mechanotransduction channel 6 protein(s) has remained elusive for decades ${ }^{13,17,18}$. Nonetheless, exquisite electrophysiological and biophysical

7 experiments have determined the force-dependent activation, localization, conductance, and selectivity of the hair-cell

8 mechanotransduction channel in ex vivo tissue explants ${ }^{10-12,15,19-23}$. These data place at least four constraints on protein

9 candidates for the channel. The protein(s) must be essential for hearing and force activated, be localized to the base of the

0 tip link, and expressed at the appropriate stage during inner-ear development. Last, the mechanotransduction channel

1 protein(s) must have a large cation selective pore with a single-channel conductance similar to that measured for the

2 mechanotransduction channel ex vivo of approximately $50-180 \mathrm{pS}^{23,24}$.

3 Several potential channel candidates have been proposed throughout the past two decades, including members of the TRP,

$4 \mathrm{HCN}, \mathrm{ENaC}$, and ASIC families of proteins ${ }^{25-40}$. Despite the initial promise of each of these candidates, they all have been

5 dismissed as none met all criteria listed above. However, genetic analyses and subsequent biochemical studies have

6 shown that at least two members of the transmembrane channel-like (TMC) family of proteins, TMC1 and TMC2, as well 
1 as three additional membrane proteins, are part of the mechanotransduction complex ${ }^{41-51}$. These proteins include the lower

2 part of the tip link made of PCDH15 with its transmembrane domain ${ }^{47,52,53}$, the tetraspan membrane protein of hair-cell

3 stereocilia (TMHS, also known as LHFPL5) ${ }^{49}$, and the transmembrane inner-ear expressed protein (TMIE) $)^{50,51}$. All are

4 essential for hearing, are localized at the base of the tip links, and might form a complex ${ }^{43,46,48-52}$. Yet, which of these, if

5 any, forms the pore of the mechanotransduction complex remains controversial ${ }^{13,17,18}$.

6 The structure of TMHS in complex with PCDH15's transmembrane domain and part of the PCDH15 ectodomain revealed

7 a dimer of dimers that is unlikely to form an ion-conducting pore ${ }^{54}$, ruling out TMHS and PCDH15 as pore-forming

8 subunits of the mechanotransduction complex. TMIE is predicted to have a single transmembrane helix ${ }^{50,55,56}$ and thus

9 unlikely to form an ion-conducting pore by itself, although there is some evidence of oligomerization ${ }^{57}$. In contrast, TMCs

0 are predicted to have multiple transmembrane domains and to adopt the topology of other membrane proteins including

1 ion channels and scramblases ${ }^{58-62}$. In addition, TMC1 satisfies the criteria necessary to be the pore-forming subunit of the

2 inner-ear hair-cell mechanotransduction complex. TMC1 is the protein product of a deafness-causing gene in mice and

3 humans $^{63-65}$ and is essential for mouse inner-ear mechanotransduction along with TMC2, a closely related homolog ${ }^{44,45,66}$.

4 Hair cells from $T m c 1 / T m c 2$ double knockout mice lack mechanotransduction currents, and transfection of $T m c 1$ or $T m c 2$

5 genes rescues hair-cell mechanotransduction ${ }^{44}$. Both TMC1 and TMC2 proteins are localized to the site of transduction at

6 the base of the tip link and are expressed at the onset of mechanotransduction with TMC1 expression dominating

7 throughout adulthood ${ }^{44-46,67}$. Importantly, several deafness-causing mutations in TMC1, including the "Beethoven"

$8 \mathrm{M} 412 \mathrm{~K}$ mutation, alter the electrophysiological properties of the hair-cell mechanotransduction channel $^{45,60,63,68}$. In

9 addition, the Danio rerio $t m c 1$ and $t m c 2 a / t m c 2 b$ orthologs are essential for fish hair-cell mechanotransduction ${ }^{69}$ and

0 electrophysiological experiments using the green sea turtle TMC1 and the budgerigar TMC2 proteins reconstituted in

1 proteoliposomes demonstrated that TMCs can form ion channels gated by membrane tension without any accessory

2 proteins $^{70}$. Together, these experimental results strongly suggest that TMC1 and TMC2 are the pore-forming subunits of

3 the mechanotransduction complex in vertebrate hair cells. Yet the mechanisms of ion permeation and activation still

4 remain poorly defined, in part because of a lack of experimentally derived structural models for TMC proteins and of the

5 complexes they may form with PCDH15, TMHS, and TMIE.

6 Bioinformatics analyses of TMC protein sequences show that TMCs are evolutionarily related to the TMEM16 family of 7 lipid scramblases and ion channels (also known as anoctamins) ${ }^{58,61,62}$. Structural studies show that TMEM16 proteins form 
1 homodimers with each monomer having ten transmembrane domains labeled $\alpha 1$ to $\alpha 10^{71-78}$. Intriguingly, bioinformatics

2 and structural analyses show that the OSCA/TMEM63 family of mechanosensitive channels have a similar homodimeric

3 architecture with each monomer featuring eleven transmembrane domains, ten of which adopt a TMEM16-like fold ${ }^{79-82}$.

4 Biochemical assays and low-resolution electron microscopy images of purified TMC1 showed that this protein also

5 assembles as a dimer ${ }^{60}$, suggesting that TMC proteins adopt the oligomeric state and folding topology of TMEM16 and

6 OSCA/TMEM63 proteins.

7 The most striking feature of TMEM16 and OSCA protein structures is their lipid-facing, groove-forming active region in

8 each monomer ${ }^{71-82}$, as opposed to a central cavity in conventional ion channels. Based on sequence and oligomeric state

9 similarities between TMEM16 and TMCs ${ }^{58,61}$, we developed TMEM16-based dimeric comparative models of TMC1 that

0 have a lipid-facing groove forming a putative pore ${ }^{59,60}$. These models were used to successfully explain ex-vivo

1 electrophysiological data obtained with hair cells expressing cysteine-substituted TMC 1 mutants ${ }^{60}$. In these experiments,

2 hair-cell channel conductivity was altered when cysteine residues predicted to be at the TMC1 pore in our model were

3 modified with blocking methanethiosulfonate (MTS) reagents, thus confirming that these residues were accessible and

4 lined the pore of the hair-cell mechanotransduction complex ${ }^{60}$. In parallel, similar TMEM16-based models were used to

5 identify the putative TMC1 pore and to guide the interpretation of experiments showing TMC1/TMC2-dependent dextran

6 permeation of hair cells ${ }^{59}$. Remarkably, deafness-causing mutations known to alter the permeation properties of the

7 mechanotransduction channel localize to the pore region in the TMEM16-based TMC1 models, further suggesting that

8 TMC proteins are the pore-forming subunits of the mechanotransduction complex and validating our TMC 1 models ${ }^{59,60}$.

9 In previous work, equilibrium molecular dynamics (MD) simulations of our TMEM16-based TMC1 comparative models

0 revealed potassium ions spontaneously exploring the putative pore, even though all models were based on structures of

1 lipid scramblases or anion channels ${ }^{60}$. This solidified the notion that TMC proteins can be cation channels, but left open

2 questions related to whether these models represented open states with the expected conductance for the

3 mechanotransduction channel in the presence of the native hair-cell transmembrane potential. Here we use non-

4 equilibrium MD simulations of human TMC1 models to predict their conductance in the presence of transmembrane

5 potentials. These simulations revealed that some TMEM16-based TMC1 models can conduct cations at rates comparable

6 to those measured for the native mechanotransduction channel and suggest that gating mechanisms might involve both

7 changes in protein conformation and membrane tension. 


\section{RESULTS}

2 A TMC1 model reveals membrane-exposed and hydrated pores. To run equilibrium and non-equilibrium MD 3 simulations of TMC1 we first created an I-TASSER ${ }^{83}$ comparative model (model 1) based on the structure of the Nectria 4 haematococca lipid scramblase TMEM16 (nhTMEM16, PDB: 4WIS; Fig. 1a) ${ }^{71}$ and on an alignment between 5 nhTMEM16 and human TMC1 sequences following Ballesteros et al. ${ }^{59}$. The TMC1 residues probed in the cysteine

6 mutagenesis experiments by Pan et al. ${ }^{60}$ that lined the pore of the transduction channel complex in murine hair cells were 7 also found in the pore-forming region of this TMC1 model (Fig. 1b). Then, we built an all-atom molecular simulation 8 system comprising the full-length TMC1 homodimer channel complex with its two pores. This system included N- and C9 terminal domains and helices $\alpha 1$ to $\alpha 10$ (Supplementary Alignment) for monomers A and B, embedded in a pure 10 palmitoyl-2-oleoyl-sn-glycero-3-phosphocholine (POPC) bilayer with explicit water at physiological ionic concentration 1 (0.150 M KCl as expected for inner-ear endolymph ${ }^{84}$; Fig. 1a). Although phosphatidylinositol 4,5-bisphosphate (PIP2) 2 and cholesterol are important for hair-cell mechanotransduction ${ }^{43,85,86}$, simulations with a pure POPC membrane are 3 essential to establish a baseline for future studies with heterogeneous lipids. During an initial 100-ns long MD 4 equilibration of the complete all-atom system without transmembrane potential (Sim1a and Sim1b; Table 1) we observed 5 stable water channels at the hydrophilic grooves formed by helices $\alpha 4$ to $\alpha 7$ of each protein monomer (Fig. 1c). Lipid 6 head-groups, initially at the typical upper and lower edges of the bilayer, provided additional stability to these water 7 channels by lining themselves along the groove and forming a hydrophilic wall that separated water from the hydrophobic bilayer core formed by lipid tails. The concentrations of water molecules in the pore of each monomer were comparable, 9 in some places, to bulk water concentrations, suggesting that each monomer may have a solvent-accessible pore able to conduct ions upon application of a transmembrane potential (Fig. 1d).

1 Further analysis of the equilibrium trajectory without a transmembrane potential (first $60 \mathrm{~ns}$ of Sim1a and Sim1b) 2 revealed that the average radius over time (Fig. S1a), the minimum pore radius as a function of time (Fig. S1b), and the 3 time-average of pore radii at different positions across the membrane (Fig. S1c) were similar for monomers A and B. 4 However, two of the pore-forming helices, $\alpha 4$ and $\alpha 6$, had distinct dynamics and adopted different conformations in each 5 TMC1 monomer. In monomer A, both $\alpha 4$ and $\alpha 6$ helices moved away from each other to widen the extracellular opening 6 of the putative pore, whereas the same helices in monomer B moved to occlude the extracellular $(\alpha 4)$ and intracellular 
1 ( $\alpha 6)$ sides of the pore (Fig. 1e,f). Consistently, the distance between residues $\mathrm{Met}^{418}$ in $\alpha 4$ and $\mathrm{Thr}^{535}$ in $\alpha 6$ increased for

2 monomer A and decreased for monomer B during the equilibrium simulation (Fig. S1d). These data suggest that relative

3 movement of helices $\alpha 4$ and $\alpha 6$ control pore aperture and the open-close equilibrium as observed for TMEM16 lipid

4 scramblases $^{75}$. Additionally, the distinct conformational changes observed in each monomer suggest that each pore in the

5 channel complex can adopt different functional states independently.

6 Interestingly, during equilibration (Sim 1a and Sim1b) a potassium ion explored the pore groove of monomer B without

7 fully crossing from one membrane side to the other (Fig. 1g; Movie 1). This occurred spontaneously in the absence of a

8 transmembrane potential, suggesting that the pore in monomer B, and likely the wider and hydrated pore in monomer A,

9 are both in potentially conductive states.

$0 \quad$ Large cationic conductance in a full-length TMC1 model. To investigate TMC1 conduction properties we performed

1 simulations in which transmembrane potentials of $-0.500 \mathrm{~V}(\operatorname{Sim} 1 \mathrm{c})$ and $-0.250 \mathrm{~V}$ (Sim1d) were applied using an external

2 electric field ${ }^{87,88}$ (Tables 1 and 2). These transmembrane potentials are large compared to physiological values (up to -

$30.125 \mathrm{~V})^{89}$, but allowed us to explore conduction events on short simulation timescales, as routinely done in MD

4 simulations of ion channel systems ${ }^{87,88,90-94}$. To determine whether helices $\alpha 4$ and $\alpha 6$ would influence conductance, we

5 chose a TMC1 conformation in which the $\mathrm{Met}^{418}-\mathrm{Thr}^{535}$ distance was large for monomer A and small for monomer B,

6 obtained after $60 \mathrm{~ns}$ of equilibration for the full-length model 1 (Fig. S1d). Thus, simulations at $-0.500 \mathrm{~V}$ and $-0.250 \mathrm{~V}$

7 started from this state. Average electrostatic potential maps confirmed the presence of the transmembrane potential and

8 showed a large potential barrier due to the lipid membrane along with narrow paths with steep potential gradients through

9 the pores (Fig. S2a,b). During both simulations, potassium ions travelled from the extracellular to the intracellular side

0 while a few chloride ions occasionally flowed in the opposite direction (Fig. S3a,b; Movie 2). The potassium ions quickly

1 traveled to the center of the pore formed by $\alpha 4, \alpha 5, \alpha 6$, and $\alpha 7$ as they moved towards its intracellular side. However, in

2 rare instances, potassium ions entered through the side of $\alpha 4$ facing the lipids, rather than through the primary permeation

3 pathway. Conductance of the TMC1 channel complex during the simulation at $-0.500 \mathrm{~V}$ was estimated to be between 66

$4 \quad \mathrm{pS}$ and $104 \mathrm{pS}$ and was mainly driven by potassium ions flowing through monomer A (80 ns; 26 permeation events total;

5 lower estimate obtained from scaling as described in Table 2 and Methods; Fig. S3a). These data are consistent with a

6 trend observed for average pore radii as a function of time, which were often larger for the pore in monomer A (Fig. S3d). 
1 Similarly, time-averaged radii at the intracellular entrance of the pore and the $\mathrm{Met}^{418}-\mathrm{Thr}^{535}$ distance as a function of time

2 were larger for monomer A (Fig. S3g,j). In contrast, conductance of the TMC1 channel complex during the simulation at -

$3 \quad 0.250 \mathrm{~V}$ was between $11 \mathrm{pS}$ and $18 \mathrm{pS}$ (250 ns; 7 permeation events; Fig. S3b), indicating a lower albeit not negligible

4 current driven by potassium ions flowing through pores of both monomers. Consistently, the average pore radii for

5 monomer $\mathrm{A}$ at $-0.250 \mathrm{~V}$ decreased while the average pore radii for monomer $\mathrm{B}$ remained at values similar to those

6 observed in the simulation carried out at $-0.500 \mathrm{~V}$ (cf. Fig. S3e and Fig. S3d). Similarly, the Met ${ }^{418}-\mathrm{Thr}^{535}$ distance as a $^{2}$

7 function of time decreased and the time-averaged radii at the intracellular entrance of the pore was similar for both

8 monomers (Fig. S3h,k). These results indicate that the pore of monomer A in our model fluctuates between two

9 conformational states, one with high conductance and one with lower conductance, while the pore of monomer B stayed

0 in a conformation with low conductance at the transmembrane potentials tested.

1 Next, we asked whether the high-conductance state observed for our TMC1 model simulated at $-0.500 \mathrm{~V}$ would remain

2 conductive at lower transmembrane potentials, namely $-0.250 \mathrm{~V}$ (Sim1e) and $-0.125 \mathrm{~V}$ (Sim1f). At the end of the

3 simulation done at $-0.500 \mathrm{~V}(\mathrm{Sim} 1 \mathrm{c})$, we instantly decreased the voltage in silico from $-0.500 \mathrm{~V}$ to $-0.250 \mathrm{~V}$ and to -0.125

$4 \mathrm{~V}$ to continue two separate simulations in parallel for $100 \mathrm{~ns}$ each. Average electrostatic potential maps showed narrow

5 paths with steep potential gradients through the pores (Fig. 2a and S2c). For the simulation done with a ramped-down

6 transmembrane potential of $-0.250 \mathrm{~V}$ (Sim1e) we observed that both pores conducted several potassium ions and recorded

7 a conductance for the TMC1 complex between $53 \mathrm{pS}$ and $83 \mathrm{pS}$ (100 ns; 13 permeation events; Fig. 2b), with monomer A

8 carrying most of the ionic current as observed at $-0.500 \mathrm{~V}$. Interestingly, two chloride ions (one per pore) permeated to

9 contribute to this conductance. Trends for average radii over time (Fig. 2c) and for the time-averaged radii at the

$0 \quad$ intracellular entrance (Fig. 2d) correlated with the conduction state of each monomer, as did the Met ${ }^{418}-\mathrm{Thr}^{535} \mathrm{distance}^{2}$

1 (Fig. 2e). During the simulation done with a ramped-down transmembrane potential of $-0.125 \mathrm{~V}$ (Sim1f) we observed

2 only two permeation events of potassium and one of chloride ions, with an estimated conductance for the TMC1 complex

3 between 25 pS and 39 pS (100 ns; 3 permeation events; Fig. S2c and S3c). The average radii over time and the time-

4 averaged radius across the membrane were similar among the pores in both monomers (Fig. S3f,i), but in this case the

$5 \mathrm{Met}^{418}-\mathrm{Thr}^{535}$ distance remained larger for pore A than for pore B (Fig. S31), suggesting that conformational dynamics of

6 lipids also contribute to determine the conductive state of each pore. 
1 A detailed analysis of the trajectory for the simulations of full-length TMC1 (model 1) in which a transmembrane

2 potential of $-0.500 \mathrm{~V}$ was applied (Sim1c) revealed a patch of hydrophobic residues that often interacted with lipids, 3 including $\mathrm{Phe}^{363}, \mathrm{Phe}^{366}, \mathrm{Leu}^{367}, \mathrm{Met}^{411}, \mathrm{Val}^{412}, \mathrm{Met}^{418}, \mathrm{Phe}^{419}, \mathrm{Leu}^{533}, \mathrm{Il}^{541}$, and Phe ${ }^{544}$ (Fig. S4a,b). These residues might

4 be essential for $\mathrm{TMC} 1$ embedding in a bilayer and may sense changes in membrane properties and tension regulating the

5 opening and closure of the pore when the membrane is stretched. An analysis of monomer A and its pore during trajectories for simulations with transmembrane potential (Sim1c through Sim1f) revealed pore-lining residues (Fig. S4c),

7 including several that interacted with potassium ions at the extracellular entrance $\left(\mathrm{Glu}^{405}, \mathrm{Glu}^{464}, \mathrm{Glu}^{523}\right)$, middle $\left(\mathrm{Ass}^{453}\right.$,

$\left.8 \mathrm{Asp}^{531}\right)$, and at the intracellular exit of the channel $\left(\mathrm{Asp}^{572}\right)$. Lipids lined most of the intracellular side of the 9 transmembrane pore (Fig. S4c), thereby supporting the dual protein-lipid nature of the TMC1 channel.

Large cationic conductance in a minimalistic TMC1 model. To predict ion conduction properties of TMC1 at longer

1 simulation timescales, we constructed a minimal molecular simulation system with a truncated version of the TMC1

2 dimer consisting of the transmembrane helices and some loops of the protein (model 1T), all with their backbones

3 constrained (Fig. 3a). Given that sequence similarity between TMC1 and nhTMEM16 is highest for transmembrane

4 domains, this model had the most reliable structural predictions at the cost of missing backbone dynamics and some intra-

5 and extra-cellular loops. To capture the high-conductance state described above, we chose a protein conformation in

6 which the $\mathrm{Met}^{418}-\mathrm{Thr}^{535}$ distance was large for both monomers A and B, obtained after a 100 ns equilibration of the full-

7 length TMC1 model 1 (Fig. S1d). Equilibration of the truncated model (Sim2a) was followed by a simulation with a

8 transmembrane potential of $-0.500 \mathrm{~V}(100 \mathrm{~ns}$; Sim2b), which when completed was used as a starting point for two

9 independent simulations in which the voltage was instantly decreased to -0.250 V (500 ns; Sim2c; Fig. 3b-d, S6a, and

$0 \mathrm{~S} 7 \mathrm{~b})$ or to $-0.125 \mathrm{~V}(500 \mathrm{~ns}$; Sim2d). Conductance of the truncated TMC1 channel complex during the simulation at -

$10.500 \mathrm{~V}$ was estimated to be between $95 \mathrm{pS}$ and $151 \mathrm{pS}(100 \mathrm{~ns} ; 47$ permeation events) and was mainly driven by

2 potassium ions flowing through monomer A (Fig. S5a), although there were 8 chloride ions contributing to the ionic

3 current. Conductance of the TMC1 channel complex during the simulation at $-0.250 \mathrm{~V}$ was estimated to be between $26 \mathrm{pS}$

4 and 41 pS (500 ns; 32 permeation events; three chloride ions; Figs. 3d, S6a and S7b), and for the simulation at $-0.125 \mathrm{~V}$

5 was between $16 \mathrm{pS}$ and $26 \mathrm{pS}$ (500 ns; 8 permeation events; cero chloride ions; Fig. S5d). These results indicate that

6 eliminating intra- and extra-cellular loops increases TMC1 conductance and decreases selectivity for potassium versus

7 chloride at a high transmembrane potential, although conduction of chloride ions remains small. The voltage-dependence 
1 of conductance observed in our backbone-constrained minimalistic TMC1 model suggests that residue side chains and

2 lipids can accommodate states of variable conductance with wider pores (Fig. S7), likely because forced passage of ions

3 with their hydration shells driven by steep electrostatic potential drops push away the malleable lipid wall present in our

$4 \quad$ TMC1 model.

5 Analysis of ion permeation during simulations of the truncated TMC1 complex at $-0.250 \mathrm{~V}$ (500 ns; 32 permeation events;

6 three chloride ions; Figs. 3d and S6a) revealed rapid passage of potassium ions, which interacted with several residues

7 that lined the pore. An example of a permeation event (Fig. 3g-j) revealed that a potassium ion was within $3 \AA$ of residues

8 that also lined the pore of the full-length TMC1 channel complex (model 1; Fig. S4c), including Q391, K406, N453,

9 E464, D531, and D572. Interactions with residues D543 and S574 were also observed. The entire permeation event lasted

$0 \quad$ less than 3 ns (Fig. 4g-j).

1 To determine whether our results with the TMC1 truncated model (model 1T) were robust or dependent on the state of the

2 lipid bilayer, we did replicate simulations with a system that included the same protein model surrounded by POPC lipids

3 in a different conformation, as these were artificially moved during the first six nanoseconds of a 46-ns long equilibration

4 (Sim2e). The resulting equilibrated system was used as a starting point for 500-ns-long simulations with transmembrane

5 potentials set to $-0.500 \mathrm{~V}(\operatorname{Sim} 2 \mathrm{f}),-0.250 \mathrm{~V}(\operatorname{Sim} 2 \mathrm{~g})$, and $-0.125 \mathrm{~V}(\mathrm{Sim} 2 \mathrm{~h})$. The conductance at a high transmembrane

6 potential was large, between $121 \mathrm{pS}$ and $192 \mathrm{pS}$, and mainly driven by potassium ions crossing through monomer A, but

7 with a significant number of chloride permeation events as well (299 permeation events; 83 chloride ions). Simulations at

8 reduced transmembrane potentials showed lower conductance values ( $26 \mathrm{pS}$ to $42 \mathrm{pS}$ at $-0.250 \mathrm{~V}$ and $8 \mathrm{pS}$ to $13 \mathrm{pS}$ at -

$90.125 \mathrm{~V})$, consistent with our previous results. We also did simulations that started from a conformation obtained after 446

0 ns of dynamics of the truncated TMC1 model at $-0.500 \mathrm{~V}(\operatorname{Sim} 2 \mathrm{f})$ and with voltage instantly decreased to $-0.250 \mathrm{~V}(500$

$1 \mathrm{~ns} ; \mathrm{Sim} 2 \mathrm{i})$ and to $-0.125 \mathrm{~V}$ (500 ns; Sim2j). Conductance was similar for both ramped-down simulations with estimates

2 between $34 \mathrm{pS}$ and $54 \mathrm{pS}$ at $-0.250 \mathrm{~V}$ and between $31 \mathrm{pS}$ and $49 \mathrm{pS}$ at $-0.125 \mathrm{~V}$. These data suggest that cation

3 conductance is robust with little dependence on the initial lipid configuration around the protein.

4 Given that truncated models had charged N- and C-termini for each helix, we also created a truncated model of the TMC1

5 protein where $\mathrm{N}$ - and $\mathrm{C}$-termini were neutralized by patching them with acetyl and N-methyl groups, respectively. After a

6 50-ns long equilibration (Sim8a), we set the transmembrane potential to $-0.500 \mathrm{~V}$ for $200 \mathrm{~ns}$ (Sim8b) and observed 
1 permeation of potassium ions with a minor contribution from chloride resulting in an estimated conductance between 83

$2 \mathrm{pS}$ and $131 \mathrm{pS}$. As the simulation progressed with decreased transmembrane potentials at $-0.250 \mathrm{mV}(500 \mathrm{~ns}$; Sim8c) or -

$30.125 \mathrm{mV}$ (500 ns; Sim8d), the conductance decreased to values between $33 \mathrm{pS}$ and $51 \mathrm{pS}$, and between $16 \mathrm{pS}$ and $26 \mathrm{pS}$,

4 respectively. The conductance values estimated for the truncated TMC1 channel complex with and without neutralization

5 of the charged terminal residues are comparable, suggesting that the presence or absence of neutral patched termini did

6 not interfere with ion conduction.

$7 \quad$ Helices $\alpha 4$ and $\alpha 6$ in open and closed TMC1 models. Our simulations of full-length and truncated TMC1 dimers (model

81 and model 1T based on nhTMEM16) suggest that TMEM16-based models are capable of cation conduction at the rates

9 expected for the hair-cell transduction channel, even in the absence of other transmembrane proteins that may be part of

0 the complex. However, similar simulations of a full-length TMC1 model based on $n h$ TMEM16 but using a different

1 sequence alignment (model 2) did not produce consistent results. Equilibration (60 ns; Sim3a and Sim3b) followed by 250

2 ns of dynamics with a transmembrane potential of $-0.500 \mathrm{~V}(\mathrm{Sim} 3 \mathrm{c})$ showed an unstable system with rupture of the lipid

3 wall at the dimeric interface and electroporation of ions resulting in an unrealistic high conductance. Conversely, there

4 were only two permeation events for a simulation at a lower transmembrane potential (-0.250 V; Sim3d). A third model

5 based on the structure of the mouse calcium-activated chloride channel TMEM16A (mmTMEM16A; PDB: 5OYB) ${ }^{77}$

6 appeared to be in a closed conformation, as corroborated by simulations of full-length (model 3) and truncated (model 3T)

7 versions that did not show ion conduction in the presence of transmembrane potentials (Sim4a to Sim4e and Sim5a to

8 Sim5d). The main difference between these models was in the relative position of $\alpha 4$, shifted toward the extracellular side

9 in model 2 (Fig. 4a) and displaced to occlude the pore in models 3 and 3T (Fig. 4b). A similar model obtained using

0 AlphaFold $2^{95,96}$, which was not simulated here, also seems to show a closed state (Fig. 4c). These results are consistent

1 with those from our equilibrium simulations of model 1 in which movement of helices $\alpha 4$ and $\alpha 6$ away from each other

2 led to pores with two different conducting states.

3 Deafness-causing mutations alter pore electrostatics. Given the success of our TMC1 simulations in reproducing

4 cationic currents at rates that are comparable to those measured for the hair-cell mechanotransduction channel, we decided

5 to use the truncated version (model 1T) to determine the effect that well-characterized deafness-causing TMC1 missense

6 mutations may have on ionic currents. The TMC1 mutations M418K (mouse M412K) ${ }^{45,63,68,97}$ and D572N (mouse 
$1 \mathrm{D} 569 \mathrm{~N})^{64,98-101}$ cause deafness in humans and mice, and both have been shown to alter resting open probability and

2 calcium permeability, likely without affecting single channel conductance ${ }^{45,68,101}$. Each mutation was introduced to both

3 monomers of the truncated model to create two mutant systems, model 1T M418K and model 1T D572N. Interestingly,

4 simulations of these systems at high transmembrane potentials (-0.500 mV; Sim6b, Sim6f, Sim7b, and Sim7f; Fig. S5b,c)

5 showed large overall conductance caused by increased flow of chloride ions. Similar trends were observed at $-0.250 \mathrm{~V}$

6 (Fig. 3d-f), with an average maximum (not scaled, see Methods) conductance of $82 \pm 23 \mathrm{pS}$ for the M418K mutant

7 (Sim6c, Sim6g, Sim6i) and of $42 \pm 38 \mathrm{pS}$ for the D572N mutant (Sim7c, Sim7g, Sim7i), compared to $45 \pm 7 \mathrm{pS}$ for the

8 wild-type protein (Sim2c, Sim2g, Sim2i). The large standard deviation for the D572N system reflects one simulation in

9 which the TMC1 complex conductance was very small ( $\operatorname{Sim} 2 \mathrm{~g})$. Despite poorer sampling over the 500-ns timescale used

0 at a more physiological transmembrane potential, our data at $-0.125 \mathrm{~V}$ (Fig. S5d-f) followed trends similar to those

1 observed at $-0.250 \mathrm{~V}$, with an average maximum conductance of $31 \pm 9 \mathrm{pS}$ for the M418K mutant (Sim6d, Sim6h, Sim6j)

2 and of $23 \pm 19 \mathrm{pS}$ for the D572N mutant (Sim7d, $\operatorname{Sim} 7 \mathrm{~h}, \operatorname{Sim} 7 \mathrm{j})$, compared to $29 \pm 18 \mathrm{pS}$ for the wild-type protein

3 (Sim2d, Sim2h, Sim2j). Notably, permeation events through monomer B remained very low, even though mutations were

4 introduced in both monomers. These results suggest that the deafness-causing mutations M418K and D572N do not

5 dramatically impair ionic currents but do change the electrostatics of the pore, which may affect calcium permeability as

6 expected (Fig. S8). Simulations of unconstrained full-length TMC1 models over longer timescales in heterogeneous

7 membranes containing negatively charged lipids such as PIP2 might be necessary to fully capture the effect of these

8 missense mutations on the dynamics and conductance of the hair-cell mechanotransduction channel.

\section{$0 \quad$ DISCUSSION}

1 Overall, our simulations of various wild-type and mutant TMC1 models indicate that transmembrane helices $\alpha 4, \alpha 5, \alpha 6$,

2 and $\alpha 7$, along with lipids surrounding these helices, form the cation-selective pore of TMC1, consistent with previous

$3 \mathrm{data}^{59,60}$. We observed that residues at helices $\alpha 4, \alpha 5, \alpha 6$, and $\alpha 7$ are water and ion accessible, and that one of our TMC1

4 models is capable of cation conduction at rates expected for the hair-cell mechanotransduction channel, further supporting

5 the presence of a pore in TMC1 and the function of this protein as the mechanotransduction channel of inner-ear hair 
1 cells. In our model where TMC1 is embedded on a membrane, lipid head groups spontaneously lined the hydrophilic

2 regions around the pore-forming helices of TMC1, building up a non-proteinaceous wall. Our simulations of these models

3 with applied transmembrane potentials suggest that each monomer can be in one of three functional states: A closed state

4 where $\alpha 4$ and $\alpha 6$ move closer together on the extracellular side (Fig. $4 \mathrm{~d}$, left panel); a lipid-occluding state where the

5 conformation of the protein is favorable for pore formation, but lipid head groups are embedded deep inside the pore

6 thereby blocking the permeation pathway (Fig. 4d, middle panel); and a third conducting state where protein and lipids

7 arrange to form a clear pathway for ion conduction (Fig. 4d - right panel). Cation-driven currents were observed for all

8 TMC1 wild-type systems where a protein-lipid pore was in an open state (model 1 and model 1T), with some minor

9 chloride component that increased in the presence of mutations M418K and D572N that altered the electrostatics of the

0 pore.

1 Residues M418 and D572 face the pore and locate in the middle of $\alpha 4$ and at the intracellular side of $\alpha 7$ of our TMC1

2 models. Mutation of these residues causes deafness in humans and mice, and electrophysiological characterization of

3 murine hair cells carrying the equivalent TMC1 M412K and D569N mutations shows that these mutations decrease

4 permeability of the mechanotransduction channel to calcium versus cesium ${ }^{45,60,68,101}$. Our simulation results show altered

5 TMC1 pore electrostatics and are consistent with experimental results. Interestingly, M418 is part of a hydrophobic patch

6 of residues that often interacts with lipids, suggesting that this residue not only contributes to ion permeation but could

7 also stabilize TMC1 in the membrane and sense changes in membrane tension. Recent work has shown that the D572N

8 mutation impairs the interaction between TMC1 and TMHS ${ }^{102}$, suggesting an additional role for residue D572 as well.

9 However, it is difficult envision how residue D572 at the intracellular side of the pore would directly interact with TMHS

0 in our TMEM16-based and AlphaFold 2 models of TMC1. Perhaps the effect of the D572N mutation is indirect and

1 relates to changes in conformation or accessibility of adjacent protein regions. Both mutations, M418K and D572N, need

2 to be studied using full-length unconstrained models of TMC1 to fully understand their effects, but our results showing

3 altered pore electrostatics are already consistent with decreased permeability to calcium.

4 The lipid bilayer plays an important role in gating of several mechanosensitive channels ${ }^{103-107}$, and it is implicated in 5 modulating hair-cell mechanotransduction and adaptation ${ }^{86,108-110}$. Our models predict a tight coupling between the TMC1 6 pore and membrane lipids, which include PIP2 and rigidifying cholesterol. The negatively charged head groups of PIP2 
1 might directly regulate the nature of the ionic current through the TMC1 pore by blocking the entrance of chloride ions at 2 the intracellular side and by further favoring cation conduction. Similarly, cholesterol, which reduces hair-cell membrane 3 fluidity and restricts channel opening ${ }^{111}$, may limit the movement of lipids around and away from TMC1 preventing its 4 opening and regulating mechanotransduction currents. A dynamic protein-lipid pore, like the one predicted here for 5 TMC1, might also allow for the passage of large cationic molecules through its pore as lipids move away to accommodate them. This would be consistent with experimental results showing that FM1-43, dextrans, and aminoglycosides can 7 permeate the hair-cell transduction channel $^{59,112-114}$.

8 Our simulations are limited by approximations in all-atom models and force-fields ${ }^{115,116}$, by simulated timescales, and by 9 the lack of an experimental structure of a TMC protein, alone or in complex with potential protein partners. However, our 0 simulation predictions provide strong support for a model in which TMC1 by itself can form a mechanosensitive ion 1 channel gated by membrane tension, in agreement with data obtained with purified TMC1 and TMC2 reconstituted in 2 liposomes $^{70}$, and as observed for bacterial channels ${ }^{103}$ and the structurally similar OSCA/TMEM163 proteins ${ }^{80}$. It is 3 possible that direct coupling to TMIE and TMHS, as well as to calcium- and integrin-binding (CIB) cytoplasmic protein 4 partners is required to tune hair-cell mechanosensitivity or to have a fully functional hair-cell mechanotransduction 5 apparatus ${ }^{43,49,117,118}$. Perhaps TMIE and TMHS or other yet to be identified component of the mechanotransduction 6 complex replaces the lipid wall observed in our simulations of TMC1 alone. It is also feasible that TMC1 and TMC2 just 7 need to be in the neighborhood of a complex formed by the tip link, TMHS, and TMIE, to feel membrane tension upon 8 stretching of PCDH15 ${ }^{119}$. Although interactions between TMC1/TMC2 and the cytoplasmic domain of PCDH15 ${ }^{120}$ 9 suggest a direct coupling of the TMC proteins with the tip link that transfers mechanical stimuli to the 0 mechanotransduction channels, the estimated number of TMC proteins at the stereocilia tip is larger than the number of 1 tip links ${ }^{24}$. This suggests the presence of additional TMC1 and TMC2 proteins that may be able to feel membrane tension 2 upon stretching of PCDH15. In this model, tonotopic conductance changes would not be limited by the discrete number of 3 channels bound per tip link, but rather could have a continuous change modulated by a variable number of TMC channels 4 around the tip link and by the membrane composition ${ }^{24,86}$. Refinement and tests of these predictions will be essential to 5 distinguish between models in which tip links directly pull on the transduction complex or rather communicate with TMC 6 channels through membrane tension. 
1

\section{METHODS}

2 Simulated Systems. Four models of human TMC1 were used for analyses. To construct the first TMC1 comparative

3 model, the alignment of the human TMC1 and the $n h$ TMEM16 lipid scramblase sequences, as published in Ballesteros et

$4 a l^{59}$, was submitted to I-TASSER (Iterative Threading ASSEmbly Refinement) a protein structure prediction web

5 server ${ }^{121,122}$. The $n h$ TMEM16 structure (PDB: $\left.4 \mathrm{WIS}\right)^{71}$ was set as a template, and the resulting monomeric model was

6 similar to I-TASSER models that used default sequence alignments. Using $\mathrm{VMD}^{123}$, a dimeric model of TMC1 was

7 constructed by aligning the predicted monomeric structure of TMC1 generated by I-TASSER with the monomers of the

8 nhTMEM16 structure (PDB: 4WIS) $)^{71}$. Clashes between $\alpha 10$ helices from monomers A and B were resolved in $\mathrm{COOT}^{124}$.

9 Monomers were moved apart from each other by $4 \AA$ in VMD to further eliminate remaining clashes. This dimer was then

0 minimized for 1000 steps in vacuum using NAMD $^{125}$ and the CHARMM36 force field ${ }^{126,127}$ before embedding it in a

1 POPC lipid bilayer using VMD and its membrane builder plugin. The protein-lipid system was then solvated using TIP3P

2 explicit water and neutralized with $0.150 \mathrm{M} \mathrm{KCl}$ to mimic the salt concentration of the endolymph ${ }^{84}$. The atomic

3 coordinates of the full-length system after Sim $1 \mathrm{~b}$ were used to construct a minimal TMC1 system (model 1T, Fig. 2a)

4 with transmembrane domains including residues $\operatorname{Lys}^{151}$ to $\operatorname{Tyr}^{215}(\alpha 1), \operatorname{Tyr}^{252}$ to $\operatorname{Gly}^{305}(\alpha 2), \operatorname{Gln}^{353}$ to $\operatorname{Ile}^{469}(\alpha 3$ to $\alpha 5)$,

$5 \operatorname{Trp}^{516}$ to $\operatorname{Pro}^{659}$ ( $\alpha 6$ to $\alpha 9$ ), and $\operatorname{Pro}^{686}$ to $\operatorname{Leu}^{730}(\alpha 10)$. The equilibrated lipids from the full-length model were part of the

6 truncated system, which was then solvated and neutralized with $0.150 \mathrm{M} \mathrm{KCl}$. Harmonic constraints $\left(k=1 \mathrm{kcal} \mathrm{mol}^{-1} \AA^{-2}\right)$

7 were applied to the entire protein backbone to hold helices in place. The system was minimized for 2000 steps prior to

8 equilibrium and non-equilibrium production runs. Replicates with scrambled lipids were obtained by applying forces to

9 water molecules within the lipid bilayer during the first six nanoseconds of equilibration (Sim2e). The VMD mutator

0 plugin was utilized on the truncated system to construct the mutant truncated TMC1 D572N and M418K systems. Counter

1 ions were added to neutralize systems after mutation, as required for electrostatic computations using the particle mesh

2 Ewald (PME) algorithm.

3 A second comparative model of TMC1 (model 2) was created using I-TASSER and an alignment of the human TMC1

4 and the $n h$ TMEM16 lipid scramblase sequences as published in Pan et al. ${ }^{60}$, with the $n h$ TMEM16 structure set as a

5 template (PDB: 4WIS) ${ }^{71}$. The I-TASSER prediction for the monomer was used to build a dimer as described above.

6 Clashes between $\alpha 10$ helices from monomers $\mathrm{A}$ and $\mathrm{B}$ were resolved in $\mathrm{COOT}^{124}$, but monomers were not further 
1 separated from each other as done for model 1. The dimer was minimized in vacuum, embedded in a POPC lipid bilayer, 2 and hydrated as done with model 1.

3 The third model used for simulations, first reported in Pan et al. ${ }^{60}$, was generated by submitting to I-TASSER the human 4 TMC1 sequence along with the structure of mouse TMEM16A (PDB: 5OYB) ${ }^{77}$. A dimer was constructed by aligning the 5 I-TASSER generated monomeric model to each monomer of the TMEM16A dimer. This dimer, which had no clashes, 6 was then embedded in a POPC bilayer and solvated, as done for models 1 and 2. The atomic coordinates of the full-length 7 system after Sim4c were used to construct a minimal TMC1 system (model 3T) with transmembrane domains including 8 residues $\mathrm{Glu}^{171}$ to $\operatorname{Tyr}^{221}(\alpha 1), \operatorname{Thr}^{265}$ to $\operatorname{Asn}^{309}(\alpha 2), \operatorname{Ser}^{337}$ to $\mathrm{Glu}^{470}$ ( $\alpha 3$ to $\left.\alpha 5\right), \operatorname{Pro}^{510}$ to $\operatorname{Ser}^{661}$ ( $\alpha 6$ to $\left.\alpha 9\right)$, and Leu ${ }^{701}$ to $9 \operatorname{Asn}^{745}(\alpha 10)$. The equilibrated lipids from the full-length model were also used to construct the system, which was then $0 \quad$ solvated and neutralized $(0.150 \mathrm{M} \mathrm{KCl})$. Harmonic constraints $\left(k=1 \mathrm{kcal} \mathrm{mol}^{-1} \AA^{-2}\right)$ were applied to the entire protein 1 backbone to hold helices in place. The system was minimized for 2000 steps prior to equilibrium and non-equilibrium 2 production runs. The fourth model of human TMC1 was obtained from the AlphaFold Protein Structure Database 3 (Q8TDI8) $)^{95,96}$. Size of simulation box for systems including models 1, 1T, 2, 3, and 3T are in Table 1.

4 Simulations. All our all-atom MD simulations ${ }^{90,92,93,115,128-134}$ were performed using NAMD 2.12 or 2.13 and the 5 CHARMM36 force field with CMAP corrections ${ }^{126,127,135}$. A 12- $\AA$ cutoff distance was employed with a force-based 6 switching function starting at $10 \AA$. Periodic boundary conditions and the PME method were used to calculate long-range 7 electrostatic interactions with a grid density greater than $1 \AA^{-3}$. A constant integration timestep of 2 fs was utilized for 8 every simulation in tandem with the SHAKE algorithm for the constraint of hydrogen atoms. To obtain a disordered 9 membrane bilayer, we did minimizations of 1000 steps followed by equilibrations lasting $0.5 \mathrm{~ns}$ with all atoms except the 0 lipid tails constrained $\left(k=1 \mathrm{kcal} / \mathrm{mol} / \AA^{2}\right)$ when indicated (Table 1$)$. These simulations were followed by another 1 minimization of 1000 steps and by an equilibration for another 0.5 ns with protein backbone atoms constrained $(k=1$ $2 \mathrm{kcal} / \mathrm{mol} / \AA^{2}$ ). All simulations were performed at $310 \mathrm{~K}$ and 1 atmosphere of pressure by using the Langevin thermostat 3 and the hybrid Nosé-Hoover piston method for pressure control. A Langevin damping coefficient of $0.1 \mathrm{ps}^{-1} \mathrm{was} \mathrm{chosen}$ 4 for the thermostat while a piston period of $200 \mathrm{fs}$ and damping timescale of $50 \mathrm{fs}$ was used for pressure control. Atomic 5 coordinates were saved every $2 \mathrm{ps}$ in all production runs. A constant electric field applied to all atoms was used in $6 \quad$ simulations with a transmembrane potential ${ }^{88}$. 
2 Simulation analysis procedures and tools. Average water concentration maps were computed using the VMD VolMap

3 Tool with a resolution of $1 \AA^{3}$. Average electrostatic maps were computed using the PME electrostatic plugin and an

4 Ewald factor of 0.25 with a grid spacing $>1 \AA^{3}$. Cell dimensions for PME calculations were set as their average for the

5 entire simulation. Both volumetric density maps and electrostatic potential maps were computed every 50 ps with systems

6 aligned using the protein backbone and starting coordinates as reference. Ionic currents were obtained by counting the

7 number of ions that sequentially traversed from bulk electrolyte, to a region between the two membrane planes, to bulk

8 electrolyte on the other side of the membrane. Membrane plane positions were defined by the average z-coordinate of the

9 phosphorus atoms of the lipid head groups for each leaflet. Residue distances were computed between C $\alpha$ atoms every 50

0 ps unless otherwise stated. The HOLE program ${ }^{136}$ was utilized to calculate pore dimensions using coordinates from

1 simulations taken every $1 \mathrm{~ns}$. Lipid atom names were changed using VMD to be recognizable by HOLE. Estimation of

2 TMC1 pore radii was difficult due to the curvaceous nature of the permeation pathway and lipid dynamics. Therefore,

3 outputs of pore profiles obtained from HOLE were first visualized in VMD for curation. Any profile that showed

4 permeation pathways that were clearly implausible were discarded prior to further analyses. Residues that lined the pore

5 more often at a given position were identified using HOLE's output. The radial distribution function $g(r)$ of lipid tails with

6 respect to $\mathrm{C}_{\alpha}$ atoms was calculated with the corresponding VMD plugin over $40 \AA$ with values compute every $0.1 \AA$.

$7 \quad$ Periodic boundary conditions were taken into consideration and selection was updated every frame. Electrostatic potential

8 and water concentration maps were plotted in MATLAB, all other data were plotted using xmgrace, and molecular images

$9 \quad$ were generated using $\mathrm{VMD}^{123}$.

1 Bulk electrolyte simulations. Control simulations of bulk electrolyte ${ }^{87,137}(0.150 \mathrm{M} \mathrm{KCl}$ electrolyte prepared in VMD 2 using the solvate and autoionize plugins; 96,243 atoms, $100 \AA^{3}$; Table S1) were performed in duplicate with identical 3 parameters to those described above. The system was minimized for 1000 steps followed by 20 ns of equilibration. Two 4 configurations, at $10 \mathrm{~ns}$ and at $20 \mathrm{~ns}$, were taken from this equilibration for subsequent simulations with an applied 5 voltage. Each configuration had a set of three simulations with a varying bias of $-0.500 \mathrm{~V},-0.250 \mathrm{~V}$, and $-0.125 \mathrm{~V}$. We 6 obtained estimates for the induced current and resistivity of the $0.150 \mathrm{M} \mathrm{KCl}$ solution by counting the number of ions that 
1 traversed the $z$ axis through an imaginary box of dimensions $l_{x}=l_{y}=50 \AA$ and $l_{z}=20,40$, or $60 \AA$. Currents were found to

2 be roughly independent of $l_{z}$. Hence, all calculations for conductance of bulk electrolyte were carried out with $l_{z}=20$. The

3 resistivity $\rho_{i}$ for system $i$ was calculated using:

$$
\rho_{i} \equiv \frac{E}{J_{i}}=\frac{V}{l} \frac{l^{2}}{I_{i}}=\frac{V l}{I_{i}}
$$

4 where $E$ is the applied electric field computed as the ratio between the voltage and the length of simulation box in $z$ 5 direction $(V / l)$, and $J_{i}$ is the current density $\left(I_{i} / l^{2}\right)$. The average resistivity of a $0.150 \mathrm{M} \mathrm{KCl}$ solution under the simulated 6 conditions was $\rho=0.278 \mathrm{Ohm} \mathrm{m}$, which is equivalent to a conductivity of $\sigma=3.62 \mathrm{~S} \mathrm{~m}^{-1}$. The estimated experimental 7 conductance of $0.150 \mathrm{M} \mathrm{KCl}$ at $308 \mathrm{~K}$ is $2.29 \mathrm{~S} \mathrm{~m}^{-1}$. Thus, currents from simulations are overestimated by $\sim 63.3 \%$. 8 However, our simulations were carried out at $310 \mathrm{~K}$, so we have used scaled conductance values $(0.63 \sigma)$ to report a lower 9 boundary for the estimates.

\section{ACKNOWLEDGEMENTS}

2 We thank Nurunisa Akyuz, David P. Corey, Bechara Kachar, Jeffrey Holt, as well as all members of the Sotomayor 3 laboratory for helpful discussions. This work was supported by the Ohio State University, by the National Institutes of 4 Health (NIDCD R01 DC0155271), and by the Human Frontier Science Program (RGP0056/2018). Simulations were 5 performed using the NCSA-Blue Waters (GLCPC), TACC-Stampede / PSC-Bridges (XSEDE MCB140226), OSC6 Owens, and OSC-Pitzer (PAS1037 and PAA0217) supercomputers. CN was supported by an OSU/NIH molecular 7 biophysics training grant (TG32GM118291). JML and JCS received Mayer's summer undergraduate research 8 fellowships. JML received an OSU undergraduate research scholarship. AB was supported by the Intramural Research 9 Program NS002945 of the NINDS to Kenton J. Swartz.

\section{AUTHOR CONTRIBUTIONS}

$2 \mathrm{SW}, \mathrm{JML}, \mathrm{AB}$, and MS designed the research. SW, JML, CN, and JCS performed the simulations. SW and JML analyzed 3 the data. SW, JML, and MS wrote the manuscript with feedback from all co-authors. 


\section{REFERENCES}

2 1. Hudspeth, A. J. Integrating the active process of hair cells with cochlear function. Nat. Rev. Neurosci. 15, 600-614 $3 \quad$ (2014).

4 2. Gillespie, P. G. \& Müller, U. Mechanotransduction by hair cells: models, molecules, and mechanisms. Cell 139, $5 \quad 33-44(2009)$.

6 3. Fettiplace, R. \& Kim, K. X. The physiology of mechanoelectrical transduction channels in hearing. Physiol. Rev. $7 \quad 94,951-986(2014)$.

8 4. Corey, D. P., Ó Maoiléidigh, D. \& Ashmore, J. F. Mechanical Transduction Processes in the Hair Cell. in 75-111 (Springer, Cham, 2017). doi:10.1007/978-3-319-52073-5_4

0 5. Angelaki, D. E. \& Cullen, K. E. Vestibular System: The Many Facets of a Multimodal Sense. Annu. Rev. Neurosci. $1 \quad 31,125-150(2008)$.

2 6. Eatock, R. A. \& Songer, J. E. Vestibular hair cells and afferents: two channels for head motion signals. Annu. Rev. Neurosci. 34, 501-34 (2011).

7. Pickles, J. O., Comis, S. D. \& Osborne, M. P. Cross-links between stereocilia in the guinea pig organ of Corti, and their possible relation to sensory transduction. Hear. Res. 15, 103-112 (1984).

8. Assad, J. a, Shepherd, G. M. \& Corey, D. P. Tip-link integrity and mechanical transduction in vertebrate hair cells. Neuron 7, 985-994 (1991).

89 9. Kachar, B., Parakkal, M., Kurc, M., Zhao, Y. -d. \& Gillespie, P. G. High-resolution structure of hair-cell tip links. Proc. Natl. Acad. Sci. 97, 13336-13341 (2000).

10. Hudspeth, A. J. \& Corey, D. P. Sensitivity, polarity, and conductance change in the response of vertebrate hair cells to controlled mechanical stimuli. Proc. Natl. Acad. Sci. U. S. A. 74, 2407-2411 (1977).

2 11. Corey, D. P. \& Hudspeth, A. J. Response latency of vertebrate hair cells. Biophys. J. 26, 499-506 (1979). $976(1983)$. 
1 13. Corey, D. P. \& Holt, J. R. Are TMCs the Mechanotransduction Channels of Vertebrate Hair Cells? J. Neurosci. 36, 10921-10926 (2016).

3 14. Ricci, A. J., Crawford, A. C. \& Fettiplace, R. Tonotopic variation in the conductance of the hair cell mechanotransducer channel. Neuron 40, 983-90 (2003).

5 15. Beurg, M., Fettiplace, R., Nam, J.-H. \& Ricci, A. J. Localization of inner hair cell mechanotransducer channels using high-speed calcium imaging. Nat. Neurosci. 12, 553-558 (2009).

16. Effertz, T., Scharr, A. L. \& Ricci, A. J. The how and why of identifying the hair cell mechano-electrical transduction channel. Pfl\{̈̈̈gers Arch. Eur. J. Physiol. 467, 73-84 (2015).

9 17. Wu, Z. \& Muller, U. Molecular Identity of the Mechanotransduction Channel in Hair Cells: Not Quiet There Yet. J. Neurosci. 36, 10927-10934 (2016).

1 18. Fettiplace, R. Is TMC1 the Hair Cell Mechanotransducer Channel? Biophys. J. 111, 3-9 (2016).

2 19. Howard, J. \& Hudspeth, A. J. Compliance of the hair bundle associated with gating of mechanoelectrical transduction channels in the bullfrog's saccular hair cell. Neuron 1, 189-199 (1988).

4 20. Crawford, A. C., Evans, M. G. \& Fettiplace, R. The actions of calcium on the mechano-electrical transducer current of turtle hair cells. J. Physiol. 434, 369-98 (1991).

21. Hudspeth, A. J. Extracellular current flow and the site of transduction by vertebrate hair cells. J. Neurosci. 2, 1-10 (1982).

22. Crawford, A. C., Evans, M. G. \& Fettiplace, R. Activation and adaptation of transducer currents in turtle hair cells. J. Physiol. 419, 405-34 (1989).

23. Ohmori, H. Mechano-electrical transduction currents in isolated vestibular hair cells of the chick. J. Physiol. 359, 189-217 (1985).

24. Beurg, M. et al. Variable number of TMC1-dependent mechanotransducer channels underlie tonotopic conductance gradients in the cochlea. Nat. Commun. 9, 2185 (2018). 
Cell. Neurosci. 12, 41 (2018).

26. Corey, D. P. et al. TRPA1 is a candidate for the mechanosensitive transduction channel of vertebrate hair cells.

Nature 432, 723-730 (2004).

4 27. Corey, D. P. What is the hair cell transduction channel? J. Physiol. 576, 23-28 (2006).

5 28. Kellenberger, S. \& Schild, L. Epithelial Sodium Channel/Degenerin Family of Ion Channels: A Variety of Functions for a Shared Structure. Physiol. Rev. 82, 735-767 (2002).

29. Rüsch, A. \& Hummler, E. Mechano-electrical transduction in mice lacking the $\alpha$-subunit of the epithelial sodium channel. Hear. Res. 131, 170-176 (1999).

30. Peng, B.-G. et al. Acid-sensing ion channel 2 contributes a major component to acid-evoked excitatory responses in spiral ganglion neurons and plays a role in noise susceptibility of mice. J. Neurosci. 24, 10167-75 (2004).

1 31. Roza, C. et al. Knockout of the ASIC2 channel in mice does not impair cutaneous mechanosensation, visceral mechanonociception and hearing. J. Physiol. 558, 659-669 (2004).

3 32. Xie, J., Price, M. P., Wemmie, J. A., Askwith, C. C. \& Welsh, M. J. ASIC3 and ASIC1 Mediate FMRFamideRelated Peptide Enhancement of $\mathrm{H}^{+}$-Gated Currents in Cultured Dorsal Root Ganglion Neurons. J. Neurophysiol. 89, 2459-2465 (2003).

33. Kwan, K. Y. et al. TRPA1 Contributes to Cold, Mechanical, and Chemical Nociception but Is Not Essential for Hair-Cell Transduction. Neuron 50, 277-289 (2006).

34. Grimm, C. et al. A helix-breaking mutation in TRPML3 leads to constitutive activity underlying deafness in the varitint-waddler mouse. Proc. Natl. Acad. Sci. U. S. A. 104, 19583-8 (2007).

35. Wu, X. et al. Hair-Cell Mechanotransduction Persists in TRP Channel Knockout Mice. PLoS One 11, e0155577 (2016).

36. Quick, K. et al. TRPC3 and TRPC6 are essential for normal mechanotransduction in subsets of sensory neurons and cochlear hair cells. Open Biol. 2, 120068-120068 (2012).

4 37. Gerka-Stuyt, J., Au, A., Peachey, N. S. \& Alagramam, K. N. Transient Receptor Potential Melastatin 1: A Hair 
Cell Transduction Channel Candidate. PLoS One 8, e77213 (2013).

38. Steigelman, K. A. et al. Polycystin-1 is required for stereocilia structure but not for mechanotransduction in inner ear hair cells. J. Neurosci. 31, 12241-50 (2011).

39. Sidi, S., Friedrich, R. W. \& Nicolson, T. NompC TRP Channel Required for Vertebrate Sensory Hair Cell Mechanotransduction. Science (80-. ). 301, 96-99 (2003).

40. Horwitz, G. C., Lelli, A., Géléoc, G. S. G. \& Holt, J. R. HCN Channels Are Not Required for Mechanotransduction in Sensory Hair Cells of the Mouse Inner Ear. PLoS One 5, e8627 (2010).

41. Pepermans, E. \& Petit, C. The tip-link molecular complex of the auditory mechano-electrical transduction machinery. Hear. Res. 330, 10-7 (2015).

42. Jaiganesh, A., Narui, Y., Araya-Secchi, R. \& Sotomayor, M. Beyond Cell-Cell Adhesion: Sensational Cadherins for Hearing and Balance. Cold Spring Harb. Perspect. Biol. a029280 (2017). doi:10.1101/cshperspect.a029280

43. Cunningham, C. L. et al. TMIE Defines Pore and Gating Properties of the Mechanotransduction Channel of Mammalian Cochlear Hair Cells. Neuron 107, 126-143.e8 (2020).

44. Kawashima, Y. et al. Mechanotransduction in mouse inner ear hair cells requires transmembrane channel-like genes. J. Clin. Invest. 121, 4796-809 (2011).

45. Pan, B. et al. TMC1 and TMC2 are components of the mechanotransduction channel in hair cells of the mammalian inner ear. Neuron 79, 504-15 (2013).

46. Kurima, K. et al. TMC1 and TMC2 Localize at the Site of Mechanotransduction in Mammalian Inner Ear Hair Cell Stereocilia. Cell Rep. 12, 1606-1617 (2015).

47. Ahmed, Z. M. et al. The tip-link antigen, a protein associated with the transduction complex of sensory hair cells, is protocadherin-15. $J$. Neurosci. 26, 7022-7034 (2006).

48. Indzhykulian, A. A. et al. Molecular Remodeling of Tip Links Underlies Mechanosensory Regeneration in Auditory Hair Cells. PLoS Biol. 11, e1001583 (2013).

49. Xiong, W. et al. TMHS is an integral component of the mechanotransduction machinery of cochlear hair cells. Cell 
151, 1283-95 (2012).

50. Gleason, M. R. et al. The transmembrane inner ear (Tmie) protein is essential for normal hearing and balance in the zebrafish. Proc. Natl. Acad. Sci. U. S. A. 106, 21347-52 (2009).

51. Zhao, B. et al. TMIE is an essential component of the mechanotransduction machinery of cochlear hair cells.

Neuron 84, 954-67 (2014).

52. Kazmierczak, P. et al. Cadherin 23 and protocadherin 15 interact to form tip-link filaments in sensory hair cells. Nature 449, 87-91 (2007).

53. Alagramam, K. N. et al. Mutations in Protocadherin 15 and Cadherin 23 Affect Tip Links and Mechanotransduction in Mammalian Sensory Hair Cells. PLoS One 6, e19183 (2011).

54. Ge, J. et al. Structure of mouse protocadherin 15 of the stereocilia tip link in complex with LHFPL5. Elife 7, (2018).

55. Karuppasamy, S., Nam, Y., Jung, H. \& Suh, J.-G. Expression of deafness protein Tmie in postnatal developmental stages of C57BL/6J mice. Lab. Anim. Res. 28, 147-50 (2012).

56. Pacentine, I. V \& Nicolson, T. Subunits of the mechano-electrical transduction channel, Tmc1/2b, require Tmie to localize in zebrafish sensory hair cells. PLoS Genet. 15, e1007635 (2019).

57. Dionne, G. Structural and Biophysical Studies of Hair Cell Mechanotransduction Proteins. (2020). doi:10.7916/D8-ZR8N-F389

58. Hahn, Y., Kim, D. S., Pastan, I. H. \& Lee, B. Anoctamin and transmembrane channel-like proteins are evolutionarily related. Int. J. Mol. Med. 24, 51-5 (2009).

59. Ballesteros, A., Fenollar-Ferrer, C. \& Swartz, K. J. Structural relationship between the putative hair cell mechanotransduction channel TMC1 and TMEM16 proteins. Elife 7, (2018).

60. Pan, B. et al. TMC1 Forms the Pore of Mechanosensory Transduction Channels in Vertebrate Inner Ear Hair Cells. Neuron 99, 736-753.e6 (2018).

61. Medrano-Soto, A. et al. Bioinformatic characterization of the Anoctamin Superfamily of Ca2+-activated ion 
channels and lipid scramblases. PLoS One 13, e0192851 (2018).

62. Kunzelmann, K. et al. Modulating Ca2+ signals: a common theme for TMEM16, Ist2, and TMC. Pflügers Arch. Eur. J. Physiol. 468, 475-490 (2016).

63. Vreugde, S. et al. Beethoven, a mouse model for dominant, progressive hearing loss DFNA36. Nat. Genet. 30, 257-258 (2002).

64. Kurima, K. et al. Dominant and recessive deafness caused by mutations of a novel gene, TMC1, required for cochlear hair-cell function. Nat. Genet. 30, 277-284 (2002).

65. Kawashima, Y., Kurima, K., Pan, B., Griffith, A. J. \& Holt, J. R. Transmembrane channel-like (TMC) genes are required for auditory and vestibular mechanosensation. Pflügers Arch. - Eur. J. Physiol. 467, 85-94 (2015).

66. Corey, D. P., Akyuz, N. \& Holt, J. R. Function and Dysfunction of TMC Channels in Inner Ear Hair Cells. Cold Spring Harb. Perspect. Med. a033506 (2018). doi:10.1101/cshperspect.a033506

67. Scheffer, D. I., Shen, J., Corey, D. P. \& Chen, Z.-Y. Gene Expression by Mouse Inner Ear Hair Cells during Development. J. Neurosci. 35, 6366-6380 (2015).

68. Beurg, M., Goldring, A. C. \& Fettiplace, R. The effects of Tmc1 Beethoven mutation on mechanotransducer channel function in cochlear hair cells. J. Gen. Physiol. 146, 233-43 (2015).

69. Smith, E. T., Pacentine, I., Shipman, A., Hill, M. \& Nicolson, T. Disruption of tmc1/2a/2b Genes in Zebrafish Reveals Subunit Requirements in Subtypes of Inner Ear Hair Cells. J. Neurosci. 40, 4457-4468 (2020).

70. Jia, Y. et al. TMC1 and TMC2 Proteins Are Pore-Forming Subunits of Mechanosensitive Ion Channels. Neuron 105, 310-321.e3 (2020).

71. Brunner, J. D., Lim, N. K., Schenck, S., Duerst, A. \& Dutzler, R. X-ray structure of a calcium-activated TMEM16 lipid scramblase. Nature 516, 207-212 (2014).

72. Brunner, J. D., Schenck, S. \& Dutzler, R. Structural basis for phospholipid scrambling in the TMEM16 family. Curr. Opin. Struct. Biol. 39, 61-70 (2016).

73. Paulino, C. et al. Structural basis for anion conduction in the calcium-activated chloride channel TMEM16A. Elife 
6, (2017).

74. Alvadia, C. et al. Cryo-EM structures and functional characterization of the murine lipid scramblase TMEM16F. Elife 8, (2019).

75. Falzone, M. E. et al. Structural basis of Ca2+-dependent activation and lipid transport by a TMEM16 scramblase. Elife 8, (2019).

76. Dang, S. et al. Cryo-EM structures of the TMEM16A calcium-activated chloride channel. Nature 552, 426-429 (2017).

77. Paulino, C., Kalienkova, V., Lam, A. K. M., Neldner, Y. \& Dutzler, R. Activation mechanism of the calciumactivated chloride channel TMEM16A revealed by cryo-EM. Nature 552, 421-425 (2017).

78. Kalienkova, V., Clerico Mosina, V. \& Paulino, C. The groovy TMEM16 family: molecular mechanisms of lipid scrambling and ion conduction. J. Mol. Biol. 166941 (2021). doi:10.1016/j.jmb.2021.166941

79. Jojoa-Cruz, S. et al. Cryo-EM structure of the mechanically activated ion channel OSCA1.2. Elife 7, (2018).

3 80. Murthy, S. E. et al. OSCA/TMEM63 are an evolutionarily conserved family of mechanically activated ion channels. Elife 7, (2018).

81. Liu, X., Wang, J. \& Sun, L. Structure of the hyperosmolality-gated calcium-permeable channel OSCA1.2. Nat. Commun. 9, 5060 (2018).

82. Zhang, M. et al. Structure of the mechanosensitive OSCA channels. Nat. Struct. Mol. Biol. 25, 850-858 (2018).

83. Yang, J. et al. The \{I-TASSER \} Suite: protein structure and function prediction. Nat. Methods 12, 7-8 (2014).

84. Bosher, S. K. \& Warren, R. L. Very low calcium content of cochlear endolymph, an extracellular fluid. Nature 273, 377-378 (1978).

1 85. Zhao, H., Williams, D. E., Shin, J.-B., Brügger, B. \& Gillespie, P. G. Large membrane domains in hair bundles specify spatially constricted radixin activation. J. Neurosci. 32, 4600-9 (2012).

3 86. Effertz, T., Becker, L., Peng, A. W. \& Ricci, A. J. Phosphoinositol-4,5-bisphosphate regulates auditory hair-cell 
mechanotransduction-channel pore properties and fast adaptation. J. Neurosci. 37, 11632-11646 (2017).

87. Aksimentiev, A. \& Schulten, K. Imaging alpha-hemolysin with molecular dynamics: ionic conductance, osmotic permeability, and the electrostatic potential map. Biophys. J. 88, 3745-61 (2005).

88. Gumbart, J., Khalili-Araghi, F., Sotomayor, M. \& Roux, B. Constant electric field simulations of the membrane potential illustrated with simple systems. Biochim. Biophys. Acta - Biomembr. 1818, 294-302 (2012).

89. Bosher, S. K. \& Warren, R. L. A study of the electrochemistry and osmotic relationships of the cochlear fluids in the neonatal rat at the time of the development of the endocochlear potential. J. Physiol. 212, 739-61 (1971).

90. Dror, R. O., Jensen, M. Ø., Borhani, D. W. \& Shaw, D. E. Exploring atomic resolution physiology on a femtosecond to millisecond timescale using molecular dynamics simulations. J. Gen. Physiol. 135, 555-562 (2010).

91. Pezeshki, S., Chimerel, C., Bessonov, A. N., Winterhalter, M. \& Kleinekathöfer, U. Understanding Ion Conductance on a Molecular Level: An All-Atom Modeling of the Bacterial Porin OmpF. Biophys. J. 97, 18981906 (2009).

92. Howard, R. J., Carnevale, V., Delemotte, L., Hellmich, U. A. \& Rothberg, B. S. Permeating disciplines: Overcoming barriers between molecular simulations and classical structure-function approaches in biological ion transport. Biochim. Biophys. acta. Biomembr. 1860, 927-942 (2018).

93. Khalili-Araghi, F. et al. Molecular dynamics simulations of membrane channels and transporters. Curr. Opin. Struct. Biol. 19, 128-37 (2009).

94. Khalili-Araghi, F., Tajkhorshid, E. \& Schulten, K. Dynamics of K+ ion conduction through Kv1.2. Biophys. J. 91, L72-4 (2006).

95. Jumper, J. et al. Highly accurate protein structure prediction with AlphaFold. Nature 1-11 (2021). doi:10.1038/s41586-021-03819-2

96. Tunyasuvunakool, K. et al. Highly accurate protein structure prediction for the human proteome. Nature 1-9 (2021). doi:10.1038/s41586-021-03828-1 
1 97. Zhao, Y. et al. A novel DFNA36 mutation in TMC1 orthologous to the Beethoven (Bth) mouse associated with autosomal dominant hearing loss in a Chinese family. PLoS One 9, e97064 (2014).

3 98. Makishima, T., Kurima, K., Brewer, C. C. \& Griffith, A. J. Early onset and rapid progression of dominant nonsyndromic DFNA36 hearing loss. Otol. Neurotol. 25, 714-9 (2004).

5 99. Kitajiri, S., Makishima, T., Friedman, T. \& Griffith, A. A novel mutation at the DFNA36 hearing loss locus reveals a critical function and potential genotype-phenotype correlation for amino acid-572 of TMC1. Clin. Genet. 71, 148-152 (2007).

100. Hilgert, N. et al. Amino acid 572 in TMC1: hot spot or critical functional residue for dominant mutations causing hearing impairment. J. Hum. Genet. 54, 188-90 (2009).

101. Beurg, M., Barlow, A., Furness, D. N. \& Fettiplace, R. A Tmc1 mutation reduces calcium permeability and expression of mechanoelectrical transduction channels in cochlear hair cells. Proc. Natl. Acad. Sci. U. S. A. 116, 20743-20749 (2019).

102. Yu, X. et al. Deafness mutation D572N of TMC1 destabilizes TMC1 expression by disrupting LHFPL5 binding. Proc. Natl. Acad. Sci. U. S. A. 117, 29894-29903 (2020).

103. Kung, C., Martinac, B. \& Sukharev, S. Mechanosensitive Channels in Microbes. Annu. Rev. Microbiol. 64, $313-$ $329(2010)$.

104. Murthy, S. E., Dubin, A. E. \& Patapoutian, A. Piezos thrive under pressure: mechanically activated ion channels in health and disease. Nat. Rev. Mol. Cell Biol. 18, 771-783 (2017).

105. Katta, S., Krieg, M. \& Goodman, M. B. Feeling Force: Physical and Physiological Principles Enabling Sensory Mechanotransduction. Annu. Rev. Cell Dev. Biol. 31, 347-371 (2015).

106. Cordero-Morales, J. F. \& Vásquez, V. How lipids contribute to ion channel function, a fat perspective on direct and indirect interactions. Curr. Opin. Struct. Biol. 51, 92-98 (2018).

107. Haswell, E. S., Phillips, R. \& Rees, D. C. Mechanosensitive channels: what can they do and how do they do it? Structure 19, 1356-69 (2011). 
1 108. Caprara, G. A., Mecca, A. A. \& Peng, A. W. Decades-old model of slow adaptation in sensory hair cells is not supported in mammals. Sci. Adv. 6, eabb4922 (2020).

109. Powers, R. J. et al. Stereocilia membrane deformation: implications for the gating spring and mechanotransduction channel. Biophys. J. 102, 201-210 (2012).

110. Powers, R. J. et al. The local forces acting on the mechanotransduction channel in hair cell stereocilia. Biophys. J. 106, 2519-2528 (2014).

111. George, S. S., Steele, C. R. \& Ricci, A. J. Rat Auditory Inner Hair Cell Mechanotransduction and Stereociliary Membrane Diffusivity Are Similarly Modulated by Calcium. iScience 23, 101773 (2020).

112. Gale, J. E., Marcotti, W., Kennedy, H. J., Kros, C. J. \& Richardson, G. P. FM1-43 dye behaves as a permeant blocker of the hair-cell mechanotransducer channel. J. Neurosci. 21, 7013-25 (2001).

113. Meyers, J. R. et al. Lighting up the Senses: FM1-43 Loading of Sensory Cells through Nonselective Ion Channels. J. Neurosci. 23, 4054-4065 (2003).

114. Kitcher, S. R. et al. ORC-13661 protects sensory hair cells from aminoglycoside and cisplatin ototoxicity. JCI insight 4, (2019).

115. Karplus, M. \& Petsko, G. A. Molecular dynamics simulations in biology. Nature 347, 631-9 (1990).

116. Vanommeslaeghe, K. \& MacKerell, A. D. CHARMM additive and polarizable force fields for biophysics and computer-aided drug design. Biochim. Biophys. Acta 1850, 861-871 (2015).

117. Giese, A. P. J. et al. CIB2 interacts with TMC1 and TMC2 and is essential for mechanotransduction in auditory hair cells. Nat. Commun. 8, (2017).

118. Liang, X. et al. CIB2 and CIB3 are auxiliary subunits of the mechanotransduction channel of hair cells. Neuron (2021). doi:10.1016/j.neuron.2021.05.007

2 119. Kung, C. A possible unifying principle for mechanosensation. Nature 436, 647-654 (2005).

120. Maeda, R. et al. Tip-link protein protocadherin 15 interacts with transmembrane channel-like proteins TMC1 and TMC2. Proc. Natl. Acad. Sci. U. S. A. 111, 12907-12 (2014). 
1 121. Zhang, Y. \{I-TASSER \} server for protein 3D structure prediction. BMC Bioinformatics 9, 40 (2008).

2 122. Roy, A., Kucukural, A. \& Zhang, Y. I-TASSER: a unified platform for automated protein structure and function prediction. Nat. Protoc. 5, 725-38 (2010).

123. Humphrey, W., Dalke, A. \& Schulten, K. VMD: Visual molecular dynamics. J. Mol. Graph. 14, 33-38 (1996).

124. Emsley, P., Lohkamp, B., Scott, W. G. \& Cowtan, K. Features and development of Coot. Acta Crystallogr. D. Biol. Crystallogr. 66, 486-501 (2010).

125. Phillips, J. C. et al. Scalable molecular dynamics with NAMD. J. Comput. Chem. 26, 1781-1802 (2005).

126. Huang, J. \& MacKerell, A. D. J. CHARMM36 all-atom additive protein force field: Validation based on comparison to NMR data. J. Comput. Chem. 34, 2135-2145 (2014).

127. Klauda, J. B. et al. Update of the CHARMM All-Atom Additive Force Field for Lipids: Validation on Six Lipid Types. J. Phys. Chem. B 114, 7830-7843 (2010).

128. Kutzner, C. et al. Insights into the function of ion channels by computational electrophysiology simulations. Biochim. Biophys. Acta 1858, 1741-52 (2016).

129. Daggett, V. \& Levitt, M. Realistic simulations of native-protein dynamics in solution and beyond. Annu. Rev. Biophys. Biomol. Struct. 22, 353-80 (1993).

130. Adcock, S. A. \& McCammon, J. A. Molecular dynamics: survey of methods for simulating the activity of proteins. Chem. Rev. 106, 1589-615 (2006).

131. Smith, J. C. \& Roux, B. Eppur si muove! The 2013 Nobel Prize in Chemistry. Structure 21, 2102-5 (2013).

132. Chavent, M., Duncan, A. L. \& Sansom, M. S. Molecular dynamics simulations of membrane proteins and their interactions: from nanoscale to mesoscale. Curr. Opin. Struct. Biol. 40, 8-16 (2016).

1 133. Jagger, B. R., Kochanek, S. E., Haldar, S., Amaro, R. E. \& Mulholland, A. J. Multiscale simulation approaches to modeling drug-protein binding. Curr. Opin. Struct. Biol. 61, 213-221 (2020).

134. Hub, J. S., Grubmüller, H. \& de Groot, B. L. Dynamics and energetics of permeation through aquaporins. What do 

available under aCC-BY-NC-ND 4.0 International license.

we learn from molecular dynamics simulations? Handb. Exp. Pharmacol. 57-76 (2009). doi:10.1007/978-3-540-

3 135. Buck, M., Bouguet-Bonnet, S., Pastor, R. W. \& MacKerell, A. D. Importance of the CMAP correction to the CHARMM22 protein force field: dynamics of hen lysozyme. Biophys. J. 90, L36-8 (2006).

5 136. Smart, O. S., Neduvelil, J. G., Wang, X., Wallace, B. A. \& Sansom, M. S. P. HOLE: A program for the analysis of the pore dimensions of ion channel structural models. J. Mol. Graph. 14, 354-360 (1996).

137. Sotomayor, M., Vásquez, V., Perozo, E. \& Schulten, K. Ion conduction through MscS as determined by electrophysiology and simulation. Biophys. J. 92, 886-902 (2007). 
bioRxiv preprint doi: https://doi.org/10.1101/2021.09.17.460860; this version posted September 18, 2021. The copyright holder for this preprint (which was not certified by peer review) is the author/funder, who has granted bioRxiv a license to display the preprint in perpetuity. It is made available under aCC-BY-NC-ND 4.0 International license.

a
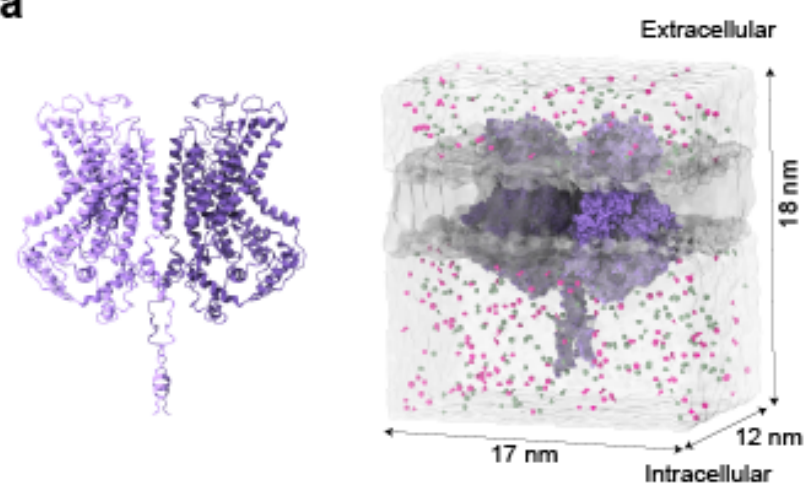

C

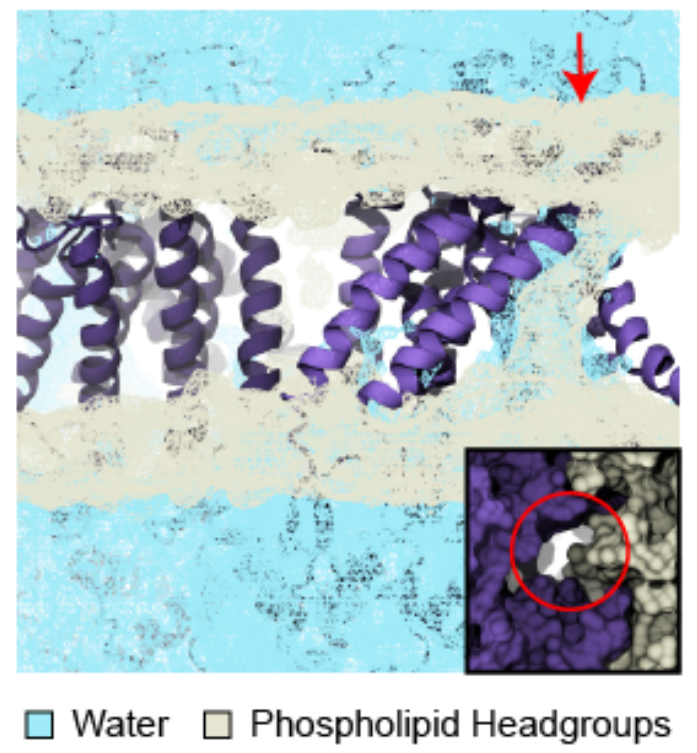

e

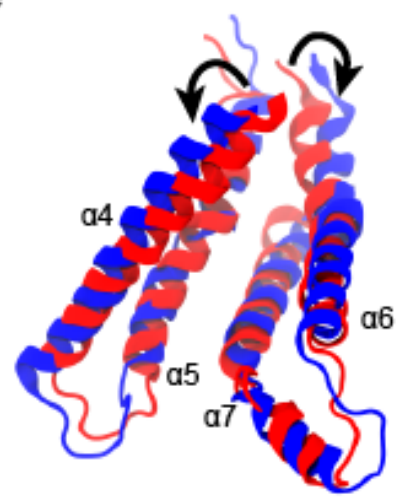

Monomer A

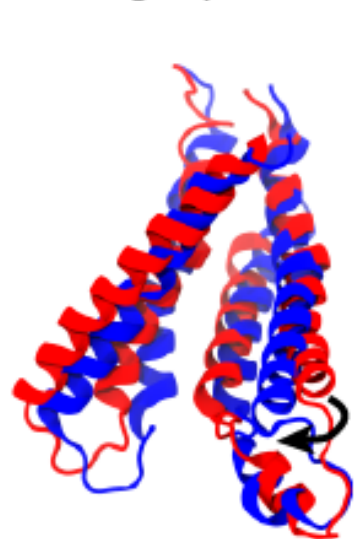

Monomer B

b

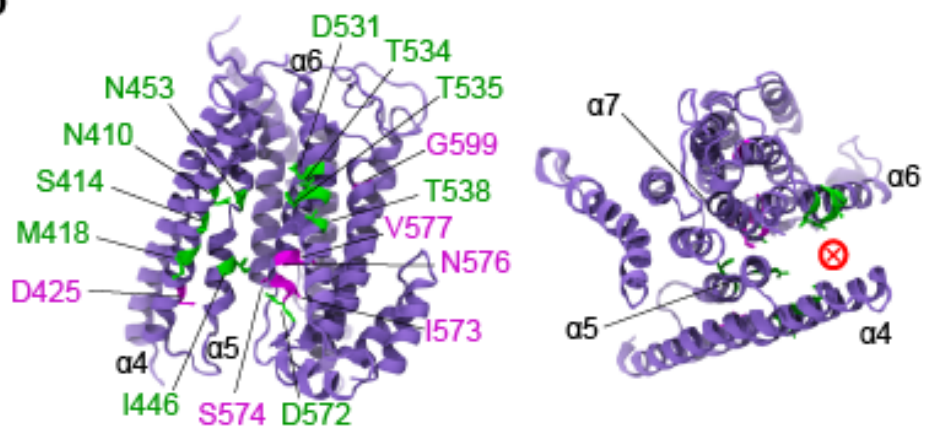

d

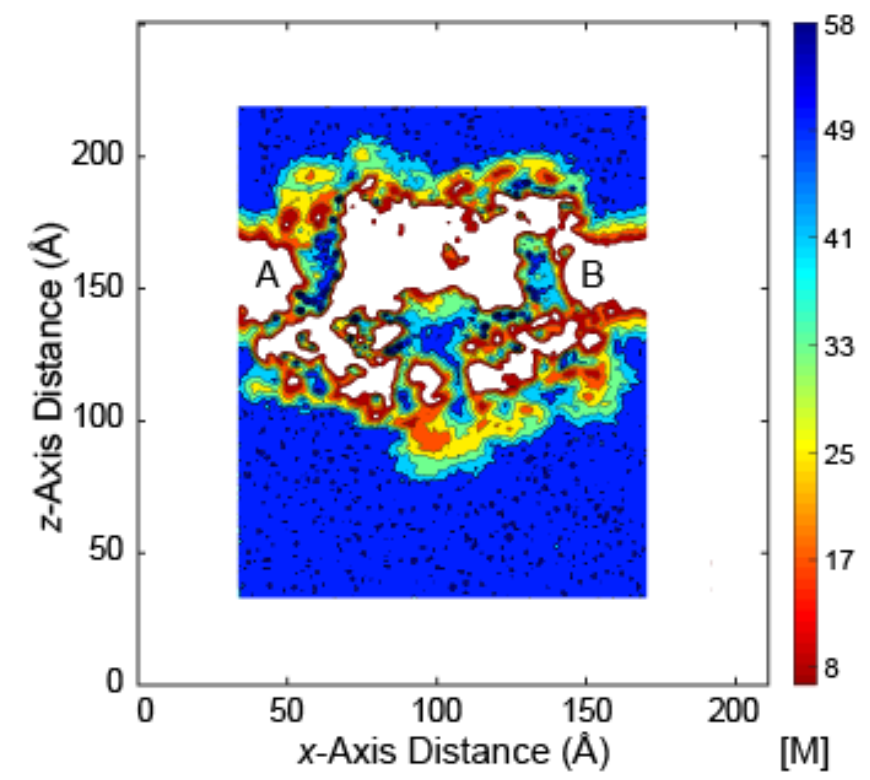

f

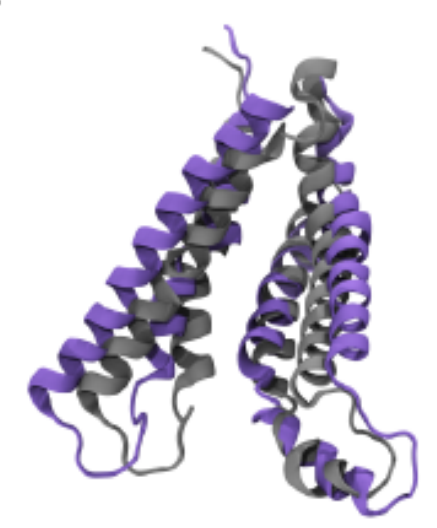

g

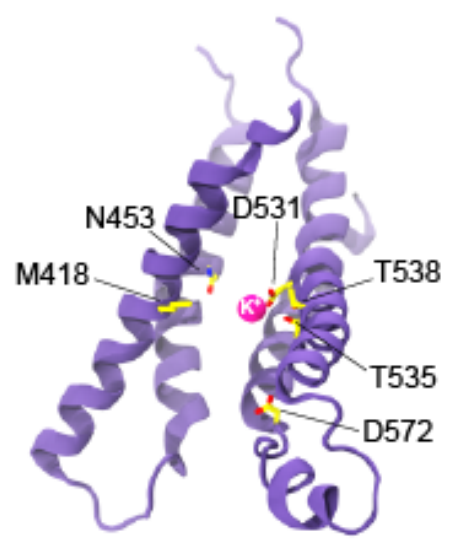

Monomer A $\square$ Monomer B

\section{Before \\ After}

Fig. 1 Lipid-exposed pore in a TMEM16-based TMC1 model. a A TMC1 dimer built using the $n h$ TMEM16 structure as a template (model 1). Simulation system is shown on the right with protein in bright and dark purple colors. Water is in transparent white, lipid membrane in transparent gray, potassium and chloride ions are pink and green, respectively. b Side and top views of TMC1 transmembrane helices from model 1 shown as ribbons (monomer). Helices $\alpha 4$ to $\alpha 7$ form the conductive groove facing lipids. Residues probed by Pan et al. ${ }^{60}$ are shown as sticks. Solvent exposed residues are shown in green, others are in magenta. Left - front view with pore facing viewer. Right - top view looking down from the extracellular side. c Density of phospholipid head groups (light yellow) and water molecules (sky blue) averaged over an equilibrium simulation (Sim1b). Inset shows top view of the pore (red circle). d Average water concentration on a plane passing through the protein (60 ns; Simlb). e Relative positions of pore-forming helices before (red) and after (blue) equilibration for monomer A (left) and monomer B (right). f TMC1 monomers A (purple) and B (gray) superposed after $60 \mathrm{~ns}$ of equilibration (Sim1b). g Potassium ion (pink) exploring the pore of monomer B during an equilibrium simulation (Sim1a and Sim1b). Key residues that line the pore are shown. 
bioRxiv preprint doi: https://doi.org/10.1101/2021.09.17.460860; this version posted September 18, 2021. The copyright holder for this preprint (which was not certified by peer review) is the author/funder, who has granted bioRxiv a license to display the preprint in perpetuity. It is made available under aCC-BY-NC-ND 4.0 International license.

a

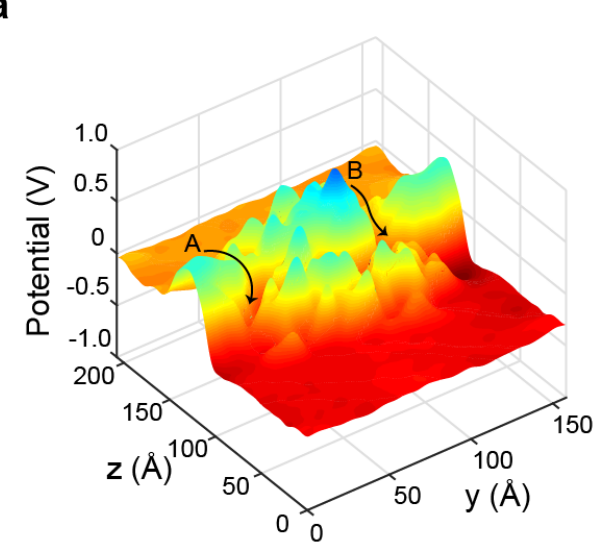

C

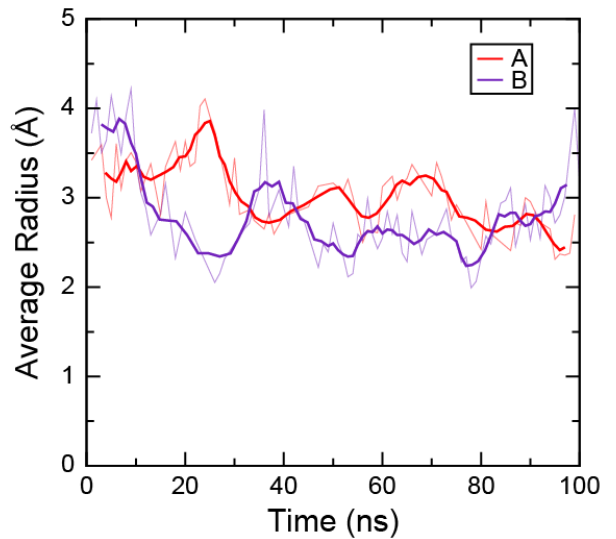

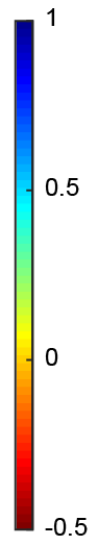

d
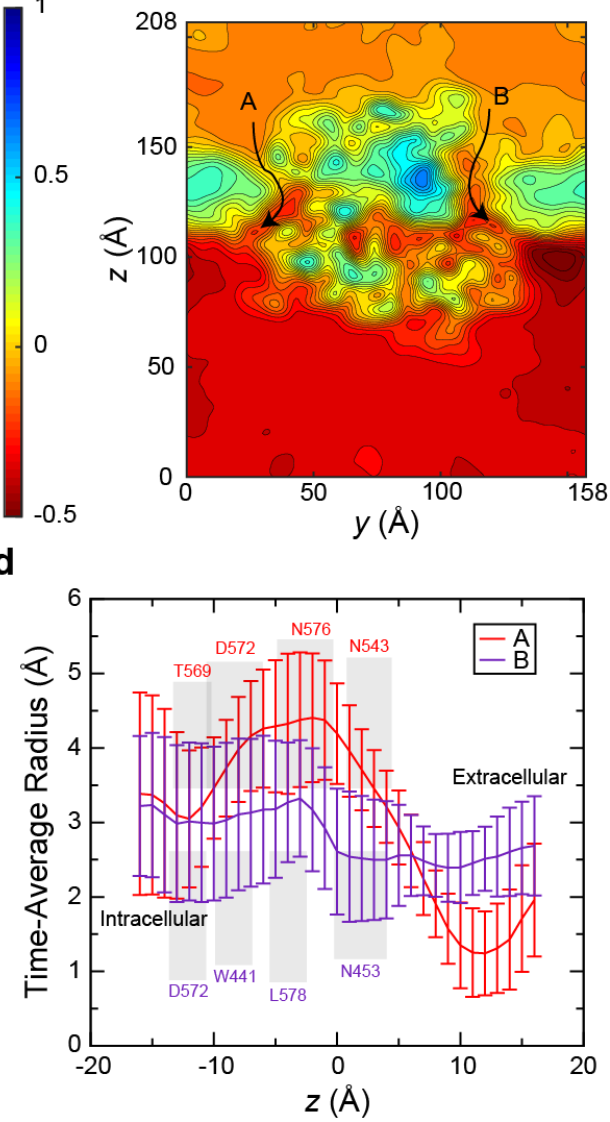

b

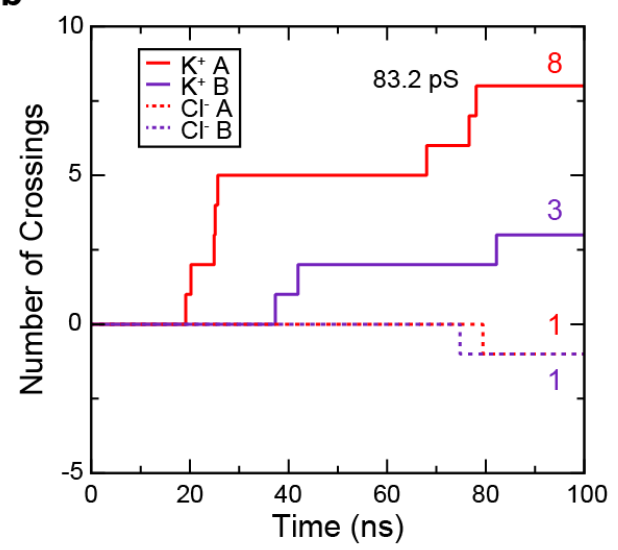

e

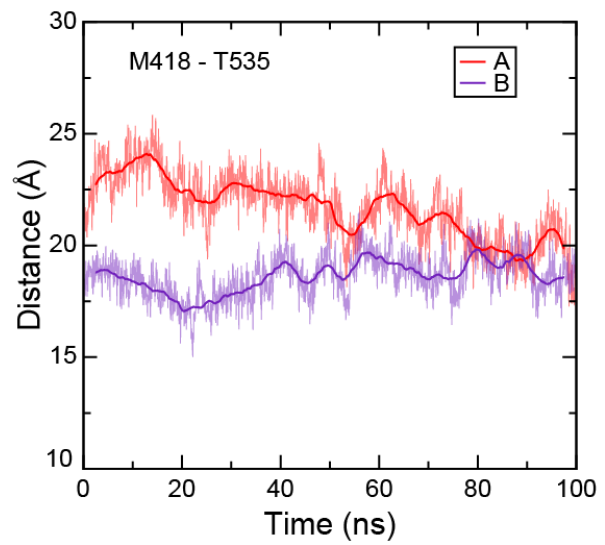

Fig. 2. Ion conduction and pore properties of TMC1. a Left - Cross-section slice through the transmembrane pores showing the electrostatic potential surface averaged over $100 \mathrm{~ns}$ of simulation of the TMC1 model at $-0.250 \mathrm{~V}$ (Sim1e). Probable ion permeation pathways shown by arrows. Right $-\mathrm{A}$ two-dimensional contour plot of the same potential surface. b Number of ion crossings as a function of time (Sim1e). Solid lines are for potassium ions going through monomers A (red) and B (indigo). Dashed lines are for chloride ions going through monomers A (red) and B (indigo). c Average radius across the pore axis $(z)$ for each monomer as a function of time (Sim1e). Transparent lines show raw data after curation (see Methods) while solid lines indicate their 5-ns running averages. d Time-averaged radii as a function of position $(z)$ along the pore axis. Value of $z$ increases from intra- to extra-cellular sides. Error bars are standard deviation. Key residues identified in the HOLE output are shown. e Separation between $\mathrm{C}_{\alpha}$ atoms

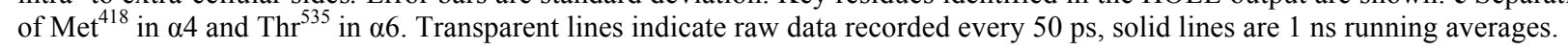


bioRxiv preprint doi: https://doi.org/10.1101/2021.09.17.460860; this version posted September 18, 2021. The copyright holder for this preprint (which was not certified by peer review) is the author/funder, who has granted bioRxiv a license to display the preprint in perpetuity. It is made available under aCC-BY-NC-ND 4.0 International license.

a

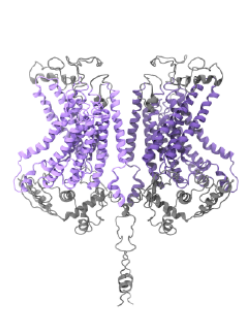

C

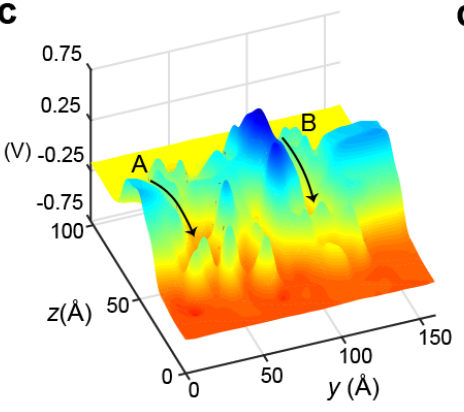

Extracellular

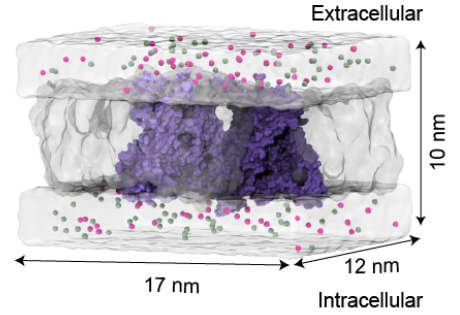

b

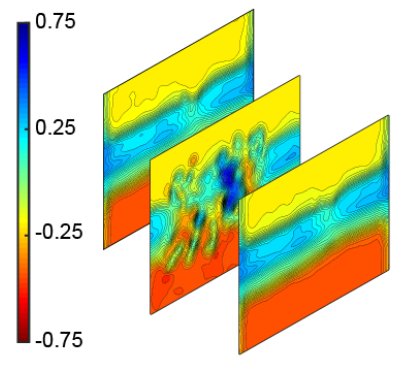

e

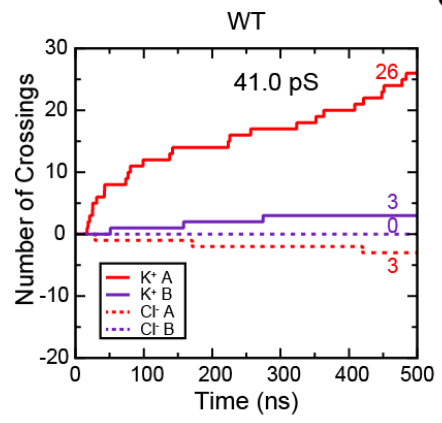

h

g $359.15 \mathrm{~ns}$
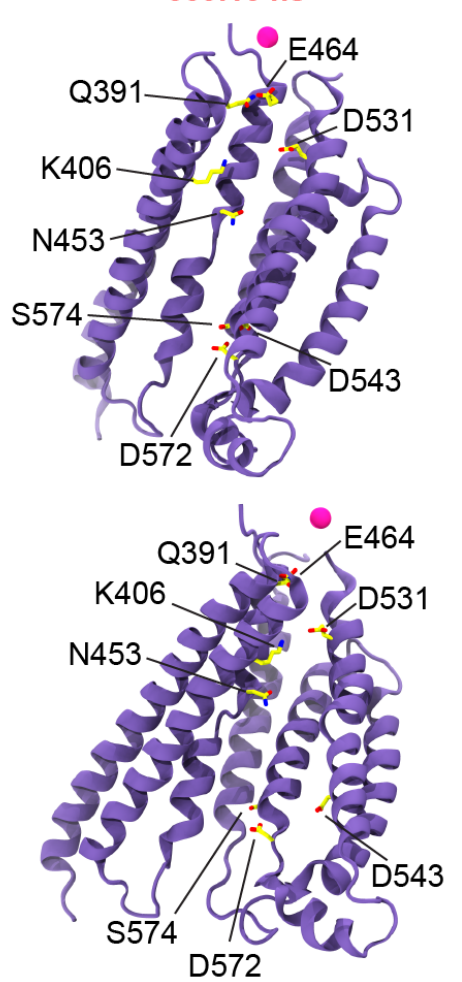

d
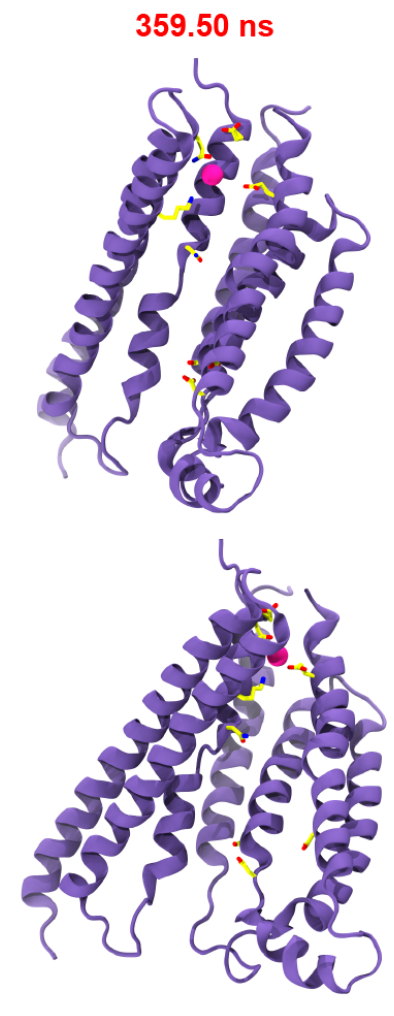

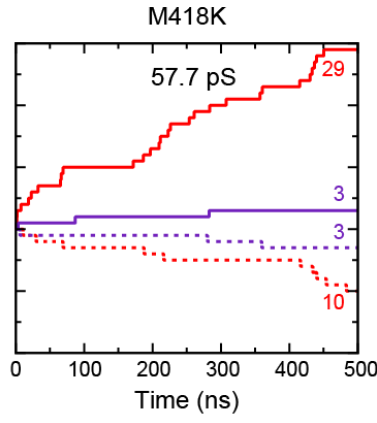

i
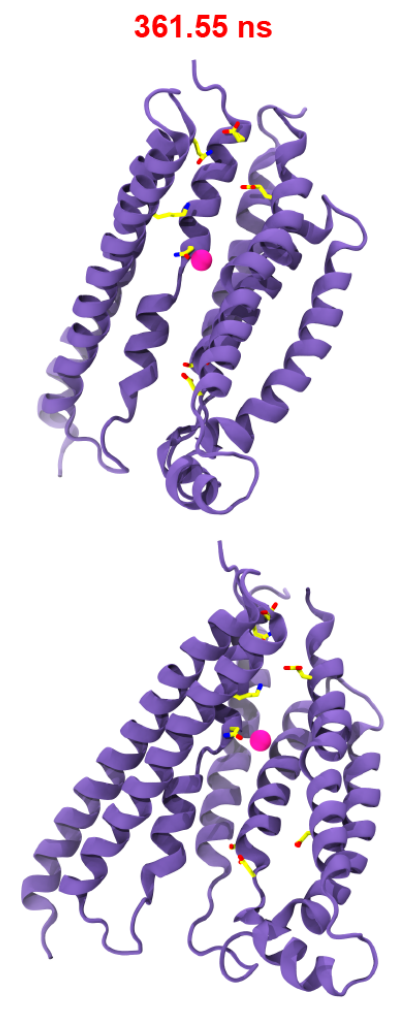

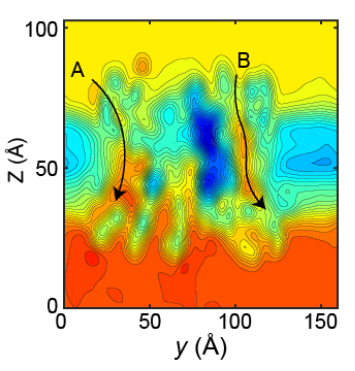

$f$

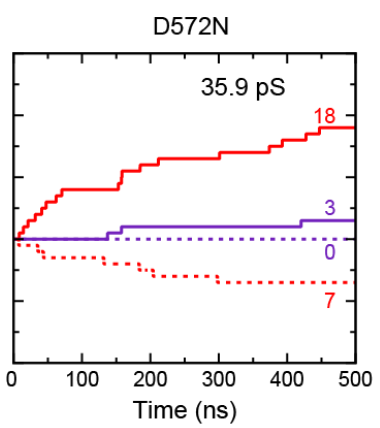

j
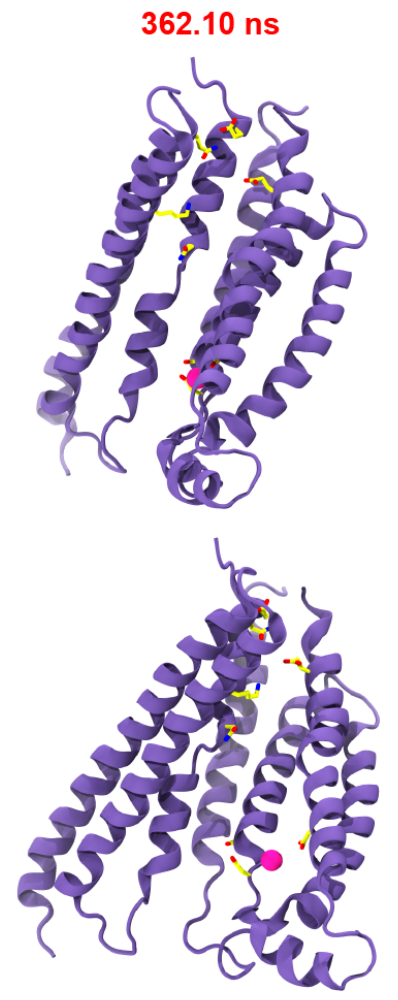

Fig. 3 Ion conduction through a minimalistic truncated model of the TMC1 dimer. a Left - truncation scheme used to create the minimalistic all atom simulation system. Excised intra- and extra-cellular regions are depicted in gray. On the right - the complete simulation system of the minimalistic model shown in surface representation. Protein is shown in bright and dark purple colors, water is shown in transparent white, lipid membrane is shown in transparent gray, potassium and chloride ions are shown as pink and green spheres, respectively. b Two-dimensional contour plots of the electrostatic potential surface averaged over $500 \mathrm{~ns}$ for the minimalistic TMC1 model at $-0.250 \mathrm{~V}$ (Sim2c). Left - Each cross section corresponds to a $y-z$ slice perpendicular to the membrane plane at three different points along the $x$ axis from back to front: a point behind the protein dimer, a point cutting through the TMC1, and a point in front of the dimer. Right - Middle cross section shown as a flat surface. Black arrows show pore regions. $\mathbf{c}$ A three-dimensional representation of the two-dimensional plot in b. d-f Ion crossing events through the pore of the wild type, M418K, and D572N truncated TMC1 systems at $-0.250 \mathrm{~V}$ (Sim2c, Sim6c, and Sim7c). Solid and dashed lines denote potassium and chloride permeation events, respectively. Also shown in Fig. S6a-c. g-j Snapshots showing a potassium permeation event during a simulation of the truncated wild-type TMC1 model at $-0.250 \mathrm{~V}(\operatorname{Sim} 2 \mathrm{c})$. Residues that were within $3 \AA$ of the ion are shown in sticks and labeled. Top and bottom rows show two different views at identical times. 
bioRxiv preprint doi: https://doi.org/10.1101/2021.09.17.460860; this version posted September 18, 2021. The copyright holder for this preprint (which was not certified by peer review) is the author/funder, who has granted bioRxiv a license to display the preprint in perpetuity. It is made available under aCC-BY-NC-ND 4.0 International license.

a
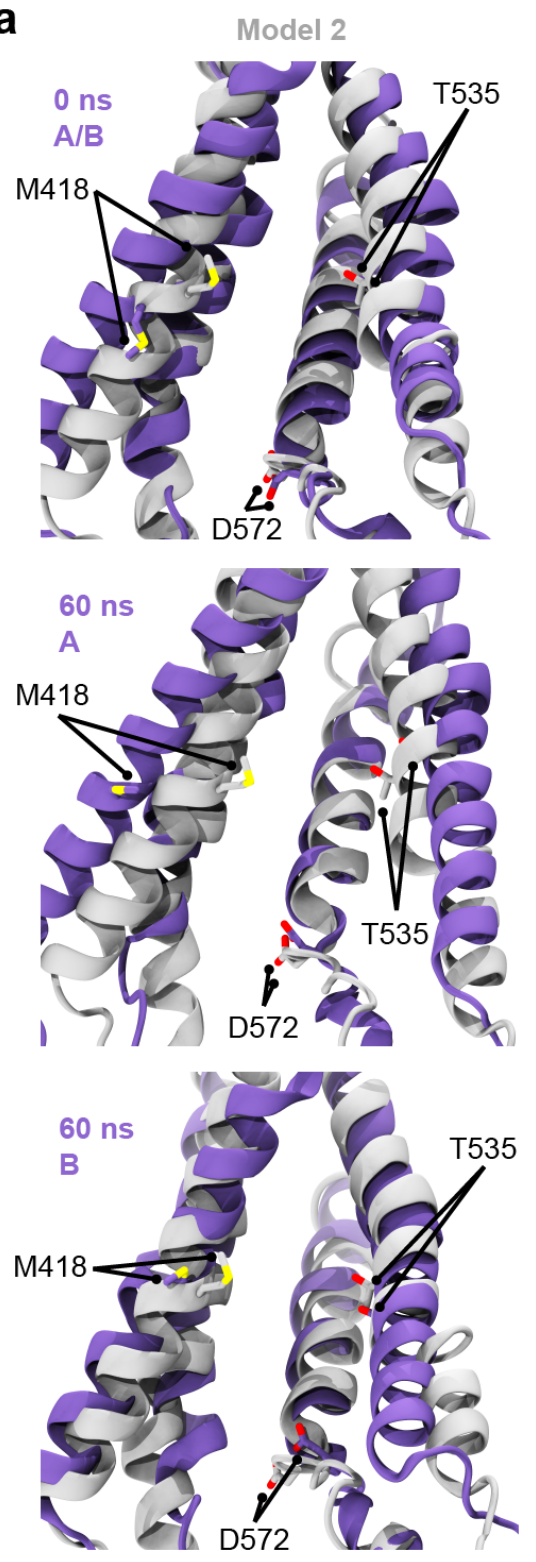

d

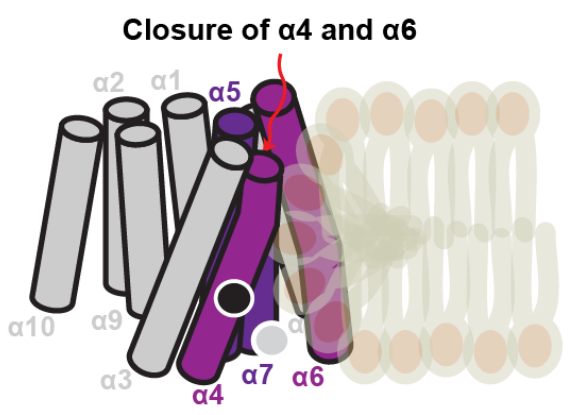

b
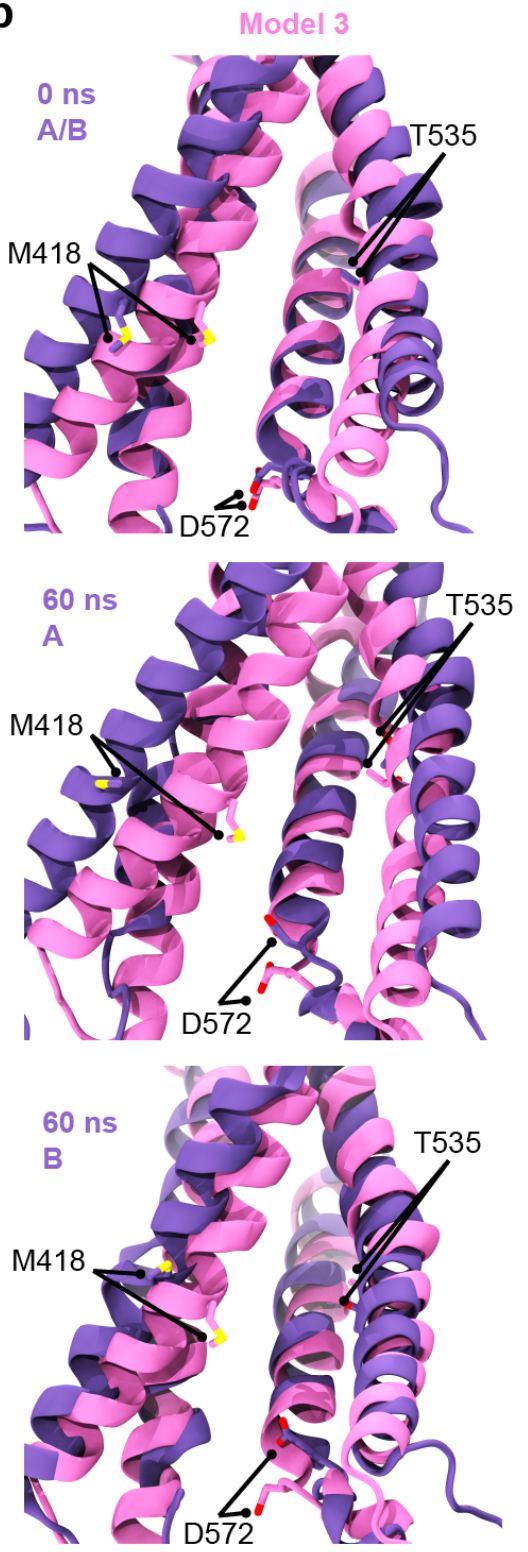

C
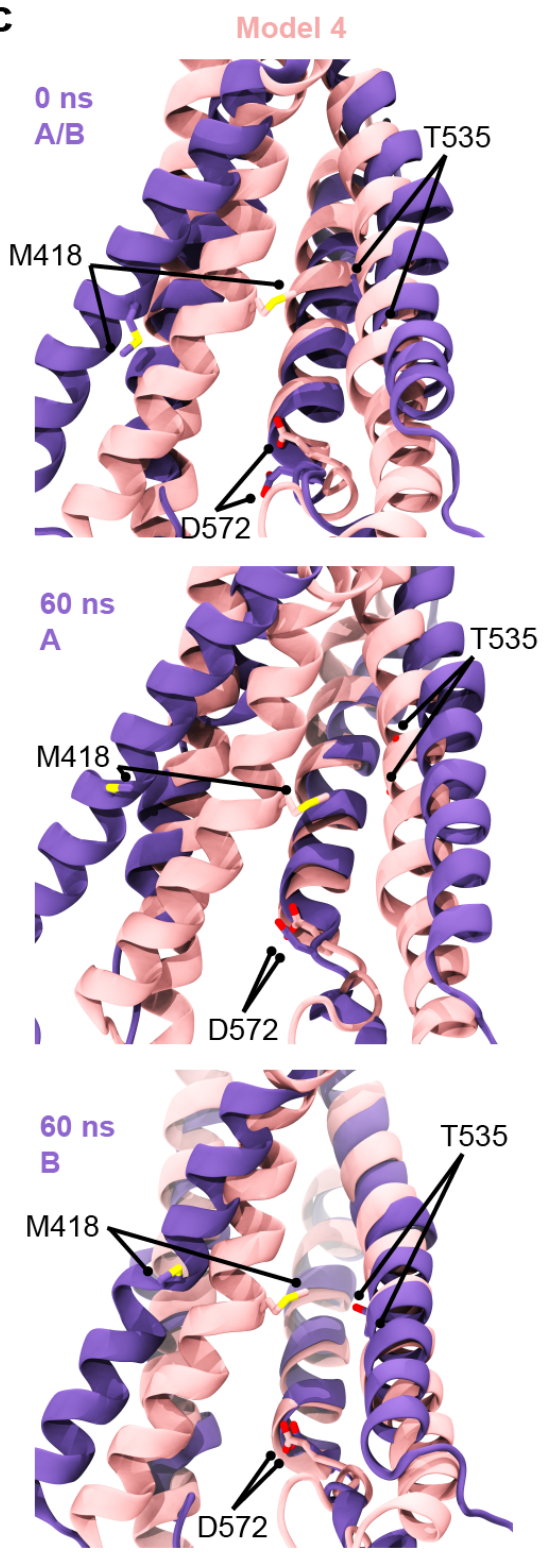
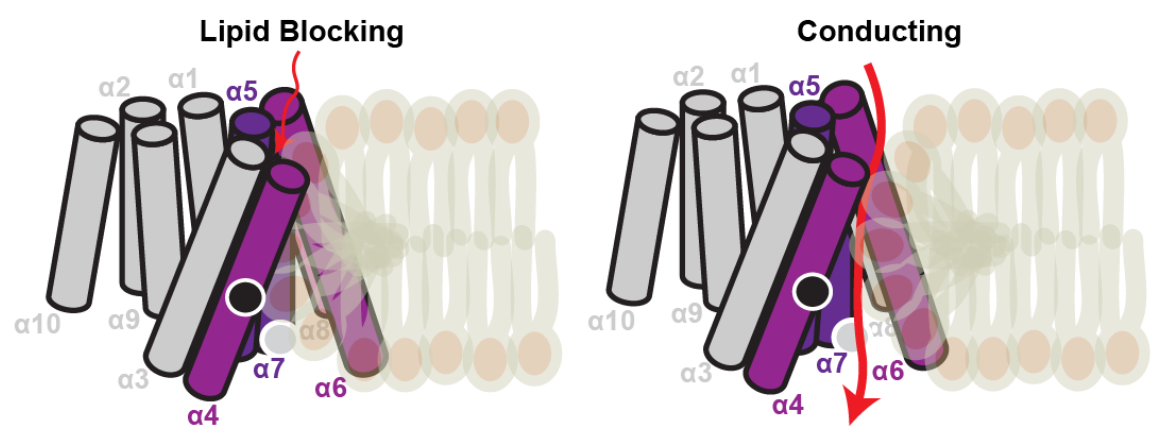

- M418K

D572N

Fig. 4 Comparison of TMC1 models. a A comparative model of TMC1 based on $n h$ TMEM16 (model 1) in purple before (top) and after 60 ns of equilibration (monomers A and B in the middle and bottom panels) overlaid with model 2 in gray. Met ${ }^{418}$, Thr ${ }^{535}$, and Asp ${ }^{572}$ are shown in licorice. b Model 1 shown as in a overlaid with a comparative model based on mmTMEM16A (model 3) in pink. c Model 1 shown as in a overlaid with an AlphaFold TMC1 model. d Schematics of three different states for TMC1. Left - Pore in a closed state due to movement of $\alpha 4$ and $\alpha 6$ to occlude the pore. Middle - Pore widens as helices $\alpha 4$ and $\alpha 6$ separate from each other and become straighter, but lipid head groups block the pore. Right Conducting state where $\alpha 4$ and $\alpha 6$ are shifted to open the pore and lipid head groups line the pore without blocking it. 
bioRxiv preprint doi: https://doi.org/10.1101/2021.09.17.460860; this version posted September 18,2021 . The copyright holder for this preprint (which was not certified by peer review) is the author/funder, who has granted bioRxiv a license to display the preprint in perpetuity. It is made available under aCC-BY-NC-ND 4.0 International license.

Table 1 - Summary of simulations

\begin{tabular}{|c|c|c|c|c|c|c|}
\hline Simulation & Start & Length (ns) & Voltage & Constraints & Modifications & Model \\
\hline $\operatorname{Sim}_{1 \mathrm{a}^{\dagger}}$ & - & 21 & 0 & backbone & - & \multirow{6}{*}{$\begin{array}{c}\text { Model } 1 \\
116 \times 173 \times 180 \AA^{3} \\
326418 \text { atoms }\end{array}$} \\
\hline Sim $1 b$ & Sim1a & 79 & 0 & - & - & \\
\hline Sim1c & Sim1b (39 ns) & 80 & -0.500 & - & - & \\
\hline Sim1d & Sim1b (39 ns) & 250 & -0.250 & - & - & \\
\hline Simle & Sim1c & 100 & -0.250 & - & - & \\
\hline Sim1f & Sim1c & 100 & -0.125 & - & - & \\
\hline $\operatorname{Sim} 2 \mathrm{a}^{\ominus}$ & Sim $1 b$ & 50 & 0 & backbone & truncated & \multirow{10}{*}{$\begin{array}{c}\text { Model 1T } \\
121 \times 170 \times 105 \AA^{3} \\
162514 \text { atoms }\end{array}$} \\
\hline $\operatorname{Sim} 2 b$ & $\operatorname{Sim} 2 \mathrm{a}$ & 100 & -0.500 & backbone & truncated & \\
\hline $\operatorname{Sim} 2 c$ & $\operatorname{Sim} 2 b$ & 500 & -0.250 & backbone & truncated & \\
\hline $\operatorname{Sim} 2 d$ & $\operatorname{Sim} 2 b$ & 500 & -0.125 & backbone & truncated & \\
\hline $\operatorname{Sim} 2 \mathrm{e}^{\S}$ & Sim $1 b$ & 46 & 0 & backbone & truncated & \\
\hline $\operatorname{Sim} 2 f$ & Sim2e & 500 & -0.500 & backbone & truncated & \\
\hline $\operatorname{Sim} 2 g$ & $\operatorname{Sim} 2 \mathrm{e}$ & 500 & -0.250 & backbone & truncated & \\
\hline $\operatorname{Sim} 2 h$ & $\operatorname{Sim} 2 \mathrm{e}$ & 500 & -0.125 & backbone & truncated & \\
\hline $\operatorname{Sim} 2 \mathrm{i}$ & $\operatorname{Sim} 2 f(446 \mathrm{~ns})$ & 500 & -0.250 & backbone & truncated & \\
\hline $\operatorname{Sim} 2 j$ & $\operatorname{Sim} 2 f(446 \mathrm{~ns})$ & 500 & -0.125 & backbone & truncated & \\
\hline $\operatorname{Sim} 3 \mathrm{a}^{\dagger}$ & - & 21 & 0 & backbone & - & \multirow{4}{*}{$\begin{array}{c}\text { Model } 2 \\
112 \times 173 \times 150 \AA^{3} \\
258896 \text { atoms }\end{array}$} \\
\hline $\operatorname{Sim} 3 b$ & Sim3a & 39 & 0 & - & - & \\
\hline $\operatorname{Sim} 3 c$ & $\operatorname{Sim} 3 b$ & 250 & -0.500 & - & - & \\
\hline Sim $3 d$ & Sim $3 b$ & 250 & -0.250 & - & - & \\
\hline $\operatorname{Sim} 4 \mathrm{a}^{\dagger}$ & - & 21 & 0 & backbone & - & \multirow{5}{*}{$\begin{array}{c}\text { Model } 3 \\
160 \times 160 \times 151 \AA^{3} \\
357562 \text { atoms }\end{array}$} \\
\hline $\operatorname{Sim} 4 b$ & Sim4a & 39 & 0 & - & - & \\
\hline $\operatorname{Sim} 4 c$ & $\operatorname{Sim} 4 b$ & 40 & 0 & - & - & \\
\hline Sim4d & $\operatorname{Sim} 4 b$ & 250 & -0.500 & - & - & \\
\hline Sim $4 \mathrm{e}$ & $\operatorname{Sim} 4 b$ & 250 & -0.250 & - & - & \\
\hline $\operatorname{Sim} 5 \mathrm{a}^{\S}$ & Sim4c & 46 & 0 & backbone & truncated & \multirow{4}{*}{$\begin{array}{c}\text { Model 3T } \\
170 \times 168 \times 106 \AA^{3} \\
231926 \text { atoms }\end{array}$} \\
\hline Sim5b & $\operatorname{Sim} 5 \mathrm{a}$ & 200 & -0.500 & backbone & truncated & \\
\hline $\operatorname{Sim} 5 c$ & Sim5a & 200 & -0.250 & backbone & truncated & \\
\hline $\operatorname{Sim} 5 d$ & Sim5a & 200 & -0.125 & backbone & truncated & \\
\hline Sim6a & Sim1b & 50 & 0 & backbone & M418K & \multirow{10}{*}{$\begin{array}{c}\text { Model } 1 \mathrm{~T} \\
121 \times 170 \times 101 \AA \\
162520 \text { atoms }\end{array}$} \\
\hline Sim6b & Sim6a & 100 & -0.500 & backbone & M418K & \\
\hline Sim6c & Sim6b & 500 & -0.250 & backbone & M418K & \\
\hline Sim6d & Sim6b & 500 & -0.125 & backbone & M418K & \\
\hline Sim6e $e^{\S}$ & Sim6b & 46 & 0 & backbone & M418K & \\
\hline Sim6f & Sim6e & 500 & -0.500 & backbone & M418K & \\
\hline Sim6g & Sim6e & 500 & -0.250 & backbone & M418K & \\
\hline Sim6h & Sim6e & 500 & -0.125 & backbone & M418K & \\
\hline Sim6i & Sim6f & 500 & -0.250 & backbone & M418K & \\
\hline Sim6j & Sim6f & 500 & -0.125 & backbone & M418K & \\
\hline $\operatorname{Sim} 7 a^{\ominus}$ & Sim1b & 50 & 0 & backbone & D572N & \multirow{10}{*}{$\begin{array}{c}\text { Model 1T } \\
121 \times 170 \times 105 \AA^{3} \\
162514\end{array}$} \\
\hline $\operatorname{Sim} 7 b$ & $\operatorname{Sim} 7 \mathrm{a}$ & 100 & -0.500 & Backbone & D572N & \\
\hline $\operatorname{Sim} 7 \mathrm{c}$ & Sim7b & 500 & -0.250 & backbone & D572N & \\
\hline $\operatorname{Sim} 7 d$ & $\operatorname{Sim} 7 b$ & 500 & -0.125 & backbone & D572N & \\
\hline Sim7e & Sim7b & 46 & 0 & backbone & D572N & \\
\hline $\operatorname{Sim} 7 f$ & Sim7e & 500 & -0.500 & backbone & D572N & \\
\hline $\operatorname{Sim} 7 g$ & Sim7e & 500 & -0.250 & backbone & D572N & \\
\hline Sim7h & Sim7e & 500 & -0.125 & backbone & D572N & \\
\hline Sim7i & $\operatorname{Sim} 7 f$ & 500 & -0.250 & backbone & D572N & \\
\hline $\operatorname{Sim} 7 j$ & $\operatorname{Sim} 7 f$ & 500 & -0.125 & backbone & D572N & \\
\hline $\operatorname{Sim} 8 a^{\ominus}$ & Sim $1 b$ & 50 & 0 & backbone & capped & \multirow{5}{*}{$\begin{array}{c}\text { Model 1T } \\
121 \times 170 \times 105 \AA^{3} \\
162604\end{array}$} \\
\hline Sim8b & Sim8a & 200 & -0.500 & backbone & capped & \\
\hline $\operatorname{Sim} 8 c$ & Sim $8 b$ & 500 & -0.250 & backbone & capped & \\
\hline Sim8d & Sim8b & 500 & -0.125 & backbone & capped & \\
\hline Total time & & 14774 & & & & \\
\hline
\end{tabular}

$2 \uparrow$ Simulations that consisted of 1000 steps of minimization, 0.5 ns of dynamics with everything but lipid tails constrained, followed by 1000 steps of 3 minimization and $0.5 \mathrm{~ns}$ of dynamics with the protein backbone constrained $\left(k=1 \mathrm{kcal}^{\mathrm{mol}}{ }^{-1} \AA^{-2}\right)$ in the $N p T$ ensemble, and 20 ns of dynamics with 4 the backbone of the transmembrane region of the protein constrained.

$5{ }^{\diamond}$ Simulations that consisted of 1000 steps of minimization, 50 ns of dynamics with the protein backbone constrained $\left(k=1 \mathrm{kcal}\right.$ mol $\left.{ }^{-1} \AA^{-2}\right)$ in the $N p T$ 6 ensemble. 
bioRxiv preprint doi: https://doi.org/10.1101/2021.09.17.460860; this version posted September 18, 2021. The copyright holder for this preprint (which was not certified by peer review) is the author/funder, who has granted bioRxiv a license to display the preprint in perpetuity. It is made available under aCC-BY-NC-ND 4.0 International license.

$1 \S$ Simulations that consisted of 1000 steps of minimization, followed by 6 ns of dynamics with the protein backbone constrained $\left(k=1\right.$ kcal mol ${ }^{-1} \AA^{-}$ $2{ }^{2}$ ) and random forces applied to water molecules within the bilayer in the NpT ensemble, and 40 ns of dynamics with the protein backbone 3 constrained in the NpT ensemble. 
bioRxiv preprint doi: https://doi.org/10.1101/2021.09.17.460860; this version posted September 18,2021 . The copyright holder for this preprint (which was not certified by peer review) is the author/funder, who has granted bioRxiv a license to display the preprint in perpetuity. It is made available under aCC-BY-NC-ND 4.0 International license.

Table 2 - Ion conduction ${ }^{\dagger}$

\begin{tabular}{|c|c|c|c|c|c|c|c|c|}
\hline Label & Length (ns) & Voltage & $\mathbf{K}_{+\mathbf{z}}^{+}$ & $\mathbf{K}_{-\mathbf{z}}^{+}$ & $\mathrm{Cl}_{+\mathrm{z}}^{-}$ & $\mathrm{Cl}_{-\mathrm{z}}^{-}$ & I pA & $\mathrm{C}(\mathrm{pS})$ \\
\hline Sim1a & 21 & 0 & 0 & 0 & 0 & 0 & 0 & 0 \\
\hline Sim1b & 79 & 0 & 0 & 0 & 0 & 0 & 0 & 0 \\
\hline Sim $1 \mathrm{c}$ & 80 & -0.500 & 0 & 23 & 3 & 0 & 52.07 & 104.13 \\
\hline Sim1d & 250 & -0.250 & 0 & 6 & 1 & 0 & 4.49 & 17.94 \\
\hline Simle & 100 & -0.250 & 0 & 11 & 2 & 0 & 20.83 & 83.30 \\
\hline Sim $1 f$ & 100 & -0.125 & 0 & 2 & 1 & 0 & 4.81 & 38.45 \\
\hline $\operatorname{Sim} 2 a$ & 50 & 0 & 0 & 0 & 0 & 0 & 0 & 0 \\
\hline $\operatorname{Sim} 2 b$ & 100 & -0.500 & 0 & 39 & 8 & 0 & 75.29 & 150.59 \\
\hline $\operatorname{Sim} 2 c$ & 500 & -0.250 & 0 & 29 & 3 & 0 & 10.25 & 41.01 \\
\hline $\operatorname{Sim} 2 d$ & 500 & -0.125 & 0 & 8 & 0 & 0 & 2.56 & 25.51 \\
\hline $\operatorname{Sim} 2 e$ & 46 & 0 & 0 & 0 & 0 & 0 & 0 & 0 \\
\hline $\operatorname{Sim} 2 f$ & 500 & -0.500 & 0 & 216 & 83 & 0 & 95.80 & 191.60 \\
\hline $\operatorname{Sim} 2 g$ & 500 & -0.250 & 0 & 28 & 4 & 0 & 10.25 & 41.01 \\
\hline $\operatorname{Sim} 2 \mathrm{~h}$ & 500 & -0.125 & 0 & 4 & 1 & 0 & 1.60 & 12.82 \\
\hline $\operatorname{Sim} 2 \mathrm{i}$ & 500 & -0.250 & 0 & 39 & 3 & 0 & 13.46 & 53.83 \\
\hline $\operatorname{Sim} 2 j$ & 500 & -0.125 & 0 & 17 & 2 & 0 & 6.09 & 48.70 \\
\hline Sim3a & 21 & 0 & 0 & 0 & 0 & 0 & 0 & 0 \\
\hline Sim $3 b$ & 39 & 0 & 0 & 0 & 0 & 0 & 0 & 0 \\
\hline $\operatorname{Sim} 3 c$ & 250 & -0.500 & 0 & 106 & 184 & 0 & 185.83 & 371.66 \\
\hline Sim3d & 250 & -0.250 & 0 & 2 & 0 & 0 & 1.28 & 5.13 \\
\hline $\operatorname{Sim} 4 \mathrm{a}$ & 21 & 0 & 0 & 0 & 0 & 0 & 0 & 0 \\
\hline $\operatorname{Sim} 4 b$ & 39 & 0 & 0 & 0 & 0 & 0 & 0 & 0 \\
\hline Sim4c & 40 & 0 & 0 & 0 & 0 & 0 & 0 & 0 \\
\hline Sim4d & 250 & -0.500 & 0 & 2 & 1 & 0 & 1.92 & 3.84 \\
\hline Sim4e & 250 & -0.250 & 0 & 1 & 2 & 0 & 1.92 & 7.69 \\
\hline $\operatorname{Sim} 5 \mathrm{a}$ & 46 & 0 & 0 & 0 & 0 & 0 & 0 & 0 \\
\hline Sim5b & 200 & -0.500 & 0 & 0 & 0 & 0 & 0 & 0 \\
\hline $\operatorname{Sim} 5 c$ & 200 & -0.250 & 0 & 0 & 0 & 0 & 0 & 0 \\
\hline $\operatorname{Sim} 5 d$ & 200 & -0.125 & 0 & 0 & 0 & 0 & 0 & 0 \\
\hline Sim6a & 50 & 0 & 0 & 0 & 0 & 0 & 0 & 0 \\
\hline Sim6b & 100 & -0.500 & 0 & 53 & 23 & 0 & 121.75 & 243.50 \\
\hline Sim6c & 500 & -0.250 & 0 & 32 & 13 & 0 & 14.42 & 57.67 \\
\hline Sim6d & 500 & -0.125 & 0 & 9 & 6 & 0 & 4.81 & 38.45 \\
\hline Sim6e & 46 & 0 & 0 & 0 & 0 & 0 & 0 & 0 \\
\hline Sim6f & 500 & -0.500 & 0 & 258 & 310 & 0 & 181.99 & 363.97 \\
\hline Sim6g & 500 & -0.250 & 0 & 34 & 45 & 0 & 25.31 & 101.25 \\
\hline Sim6h & 500 & -0.125 & 0 & 8 & 5 & 0 & 4.17 & 33.28 \\
\hline Sim6i & 500 & -0.250 & 0 & 38 & 30 & 0 & 21.79 & 87.15 \\
\hline Sim6j & 500 & -0.125 & 0 & 4 & 4 & 0 & 2.56 & 20.51 \\
\hline Sim7a & 50 & 0 & 0 & 0 & 0 & 0 & 0 & 0 \\
\hline $\operatorname{Sim} 7 b$ & 100 & -0.500 & 0 & 23 & 15 & 0 & 60.88 & 121.75 \\
\hline $\operatorname{Sim} 7 \mathrm{c}$ & 500 & -0.250 & 0 & 21 & 7 & 0 & 8.97 & 35.88 \\
\hline Sim7d & 500 & -0.125 & 0 & 8 & 9 & 0 & 5.45 & 43.57 \\
\hline Sim7e & 46 & 0 & 0 & 0 & 0 & 0 & 0 & 0 \\
\hline $\operatorname{Sim} 7 f$ & 500 & -0.500 & 0 & 156 & 81 & 0 & 75.93 & 151.87 \\
\hline $\operatorname{Sim} 7 g$ & 500 & -0.250 & 0 & 5 & 1 & 0 & 1.92 & 7.69 \\
\hline Sim7h & 500 & -0.125 & 0 & 6 & 1 & 0 & 2.24 & 17.94 \\
\hline Sim7i & 500 & -0.250 & 0 & 40 & 25 & 0 & 20.83 & 83.30 \\
\hline $\operatorname{Sim} 7 j$ & 500 & -0.125 & 0 & 2 & 1 & 0 & 0.96 & 7.69 \\
\hline Sim8a & 50 & 0 & 0 & 0 & 0 & 0 & 0 & 0 \\
\hline Sim8b & 200 & -0.500 & 0 & 77 & 5 & 0 & 65.68 & 131.36 \\
\hline Sim8c & 500 & -0.250 & 0 & 38 & 2 & 0 & 12.82 & 51.26 \\
\hline Sim8d & 500 & -0.125 & 0 & 8 & 2 & 0 & 3.20 & 25.63 \\
\hline
\end{tabular}

${ }^{\dagger}$ Events, currents and conductance values are reported for combined monomers A and B. 
SUPPLEMENTARY MATERIAL

\section{IN SILICO ELECTROPHYSIOLOGY OF INNER-EAR MECHANOTRANSDUCTION CHANNEL}

\section{TMC1 MODELS}

Sanket Walujkar ${ }^{1,2} *$, Jeffrey M. Lotthammer ${ }^{1}$, Collin R. Nisler ${ }^{1,3}$, Joseph C. Sudar ${ }^{1}$, Angela Ballesteros ${ }^{4}$,

$$
\text { Marcos Sotomayor }{ }^{1,2,3} \neq
$$

1 Department of Chemistry and Biochemistry, The Ohio State University

484, W $12^{\text {th }}$ Ave, Columbus, OH 43201

2 Chemical Physics Graduate Program, The Ohio State University

484, W $12^{\text {th }}$ Ave, Columbus, OH 43201

3 Biophysics Graduate Program, The Ohio State University

484, W $12^{\text {th }}$ Ave, Columbus, OH 43201

4 Molecular Physiology and Biophysics Section, Porter Neuroscience Research Center

National Institute of Neurological Disorders and Stroke

National Institutes of Health, Bethesda, MD 20892

September 2021

* Co-first authors

₹ Corresponding author 


\section{MOVIES}

3 Movie 1 Side view of the TMC1 channel pore at $0 \mathrm{~V}$ (monomer B). A potassium ion (pink) is seen exploring the pore 4 without fully permeating from one membrane side to the other during an equilibrium simulation (Sim1a and Sim1b; 60 5 ns). Protein is shown in purple, phosphorus atoms from lipid head groups are shown as light-yellow spheres. Water 6 molecules, lipid tails, and protein side chains are omitted for clarity.

8 Movie 2 Side view of the TMC1 channel pore at $-0.500 \mathrm{~V}$ (monomer A). Potassium (pink) and chloride ions (green) were 9 observed to fully permeate from one membrane side to the other (Sim1c; $80 \mathrm{~ns}$ ). System shown as in Movie 1. 
a

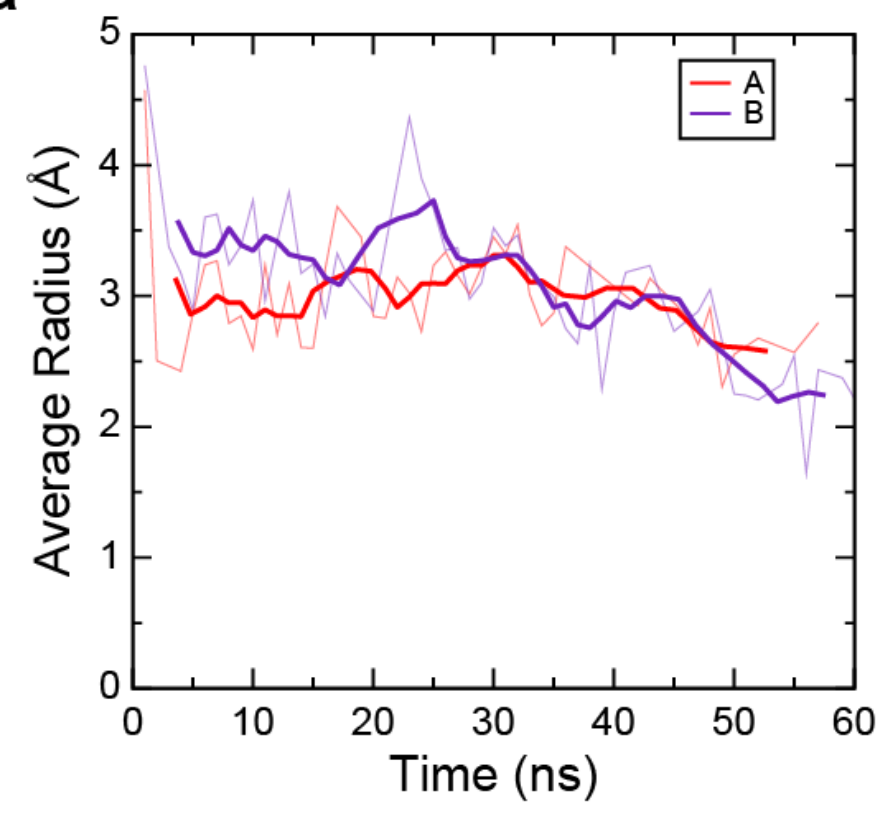

C

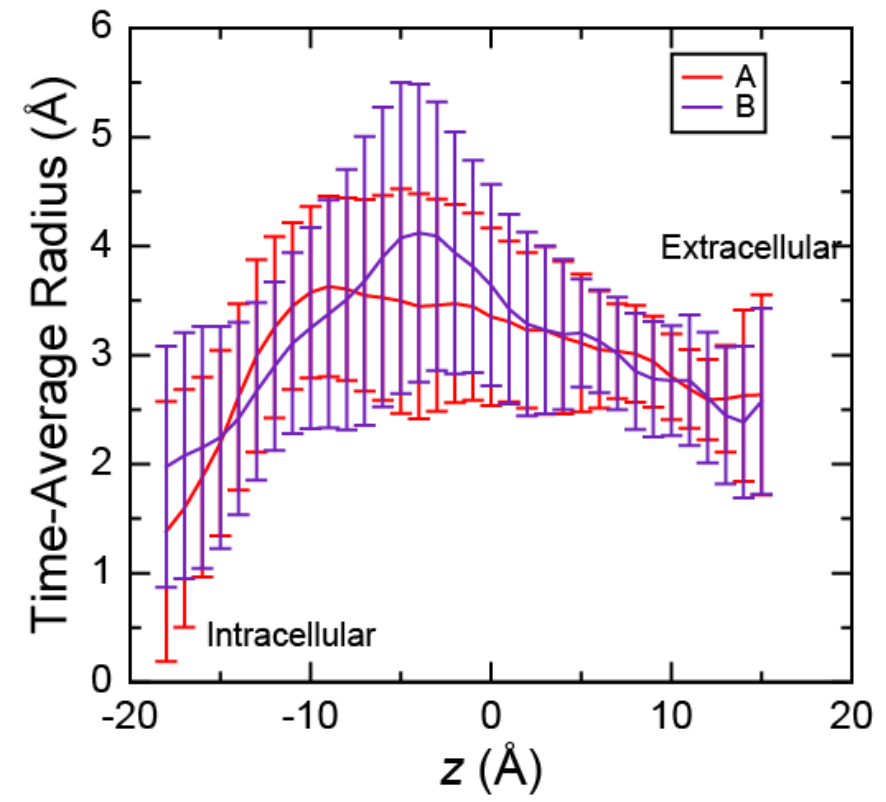

b

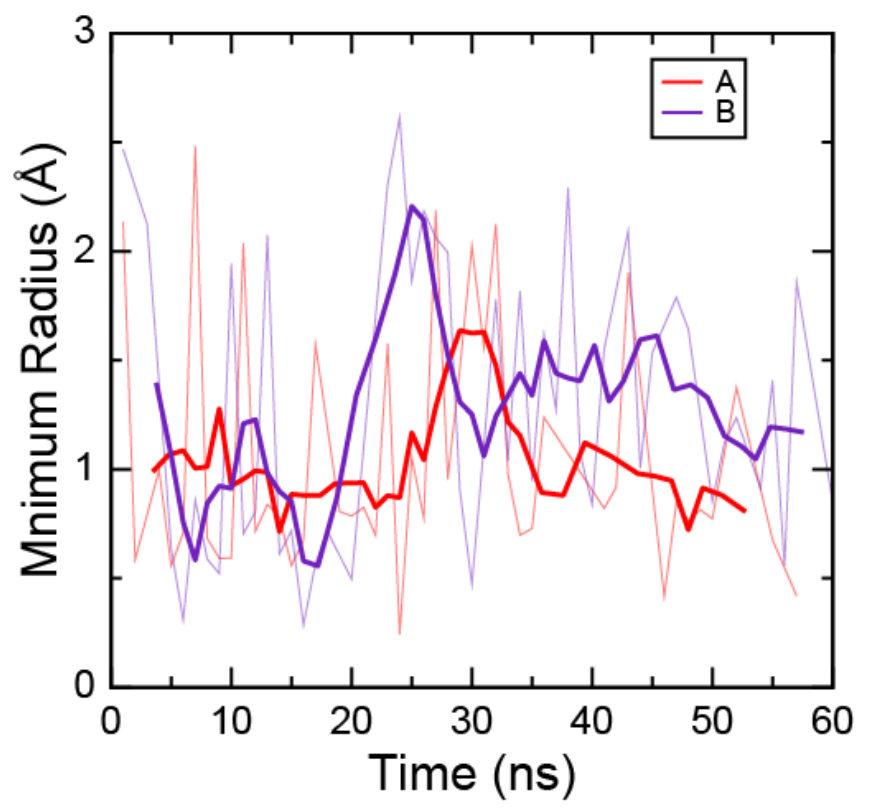

d

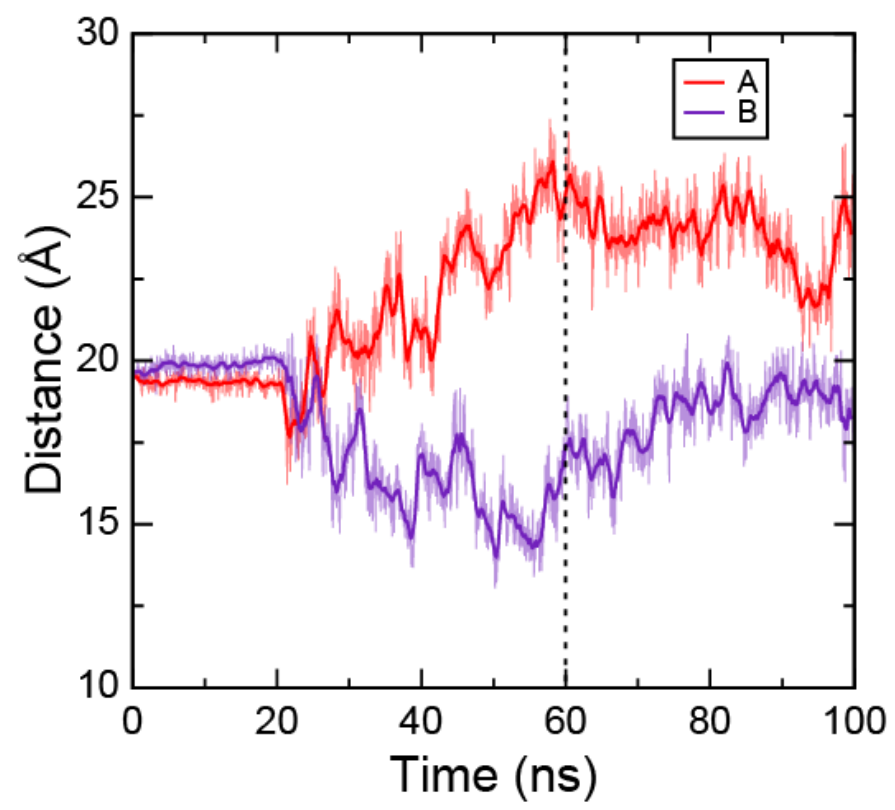

Fig. S1 Pore properties during equilibration of full-length TMC1 model 1. a Average radius across the pore axis $(z)$ for each monomer as a function of time during Sim1a (21 ns) and Sim1b (first $39 \mathrm{~ns}$ ). Transparent lines are curated raw data and solid lines are their 5-ns running averages. b Minimum radii of each monomer pore as a function of time during the same $60 \mathrm{~ns}$ of simulation as in a. c Time-average radii as a function of position $(z)$ along the pore axis computed over 60 ns of Sim1a and Sim1b. Value of $z$ increases from intra- to extra-cellular sides. Error bars are standard deviation. d Separation between $\mathrm{C}_{\alpha}$ atoms of $\mathrm{Met}^{418}$ in $\alpha 4$ and $\mathrm{Thr}^{535}$ in $\alpha 6$ (Sim1a and Sim1b). Transparent lines indicate raw data recorded every $50 \mathrm{ps}$, solid lines are $1 \mathrm{~ns}$ running averages. Vertical dashed line marks starting point for simulations with transmembrane potential (Sim1c and Sim1d). 
bioRxiv preprint doi: https://doi.org/10.1101/2021.09.17.460860; this version posted September 18, 2021. The copyright holder for this preprint (which was not certified by peer review) is the author/funder, who has granted bioRxiv a license to display the preprint in perpetuity. It is made available under aCC-BY-NC-ND 4.0 International license.

a
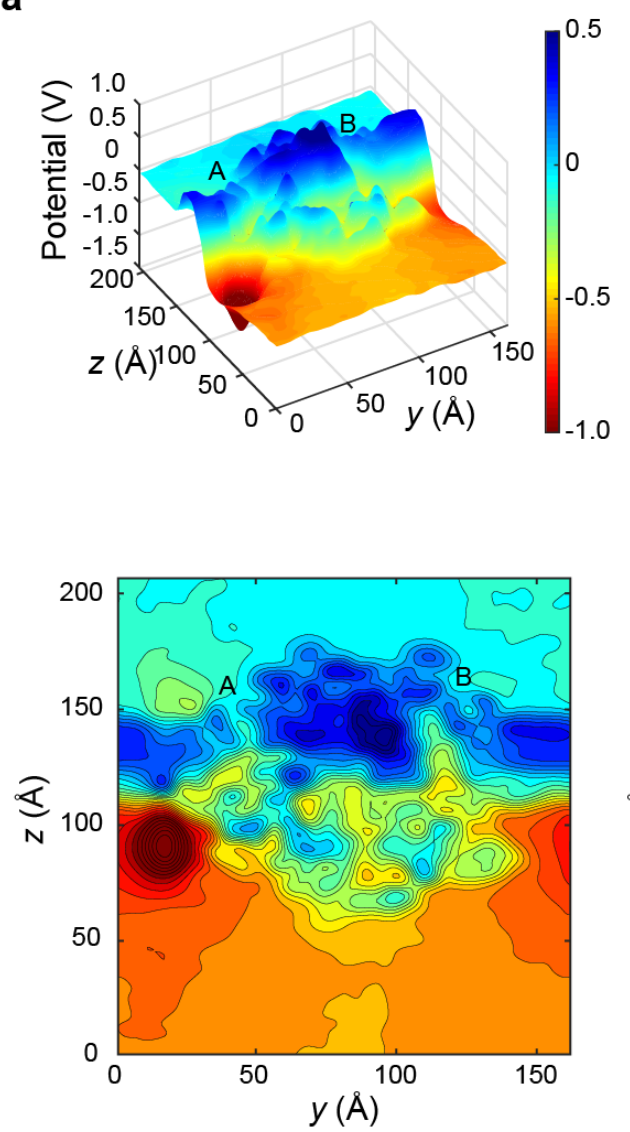

b
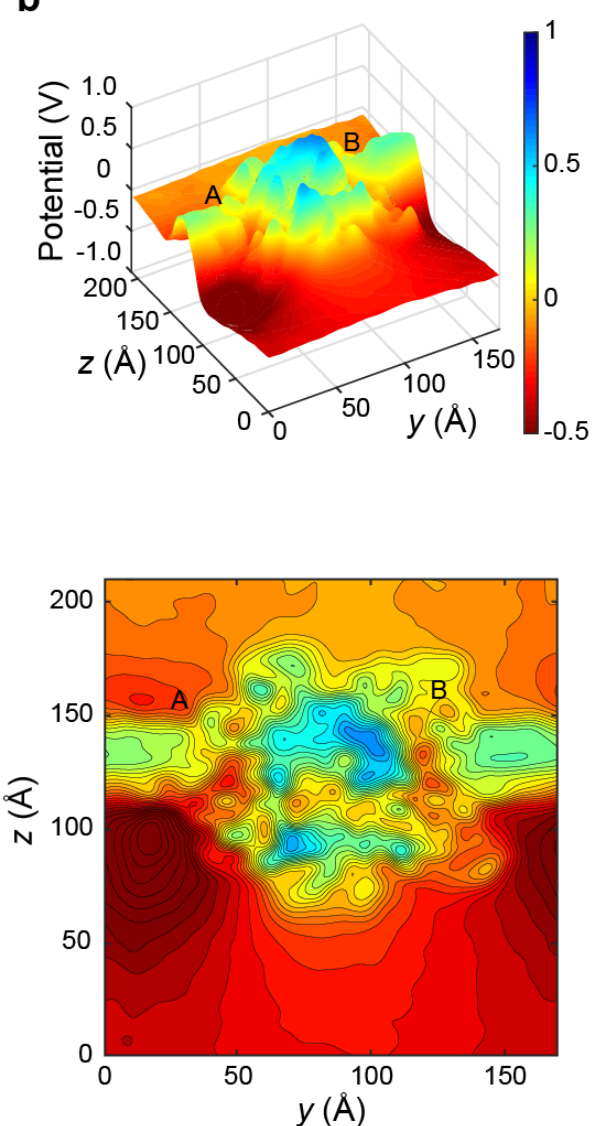
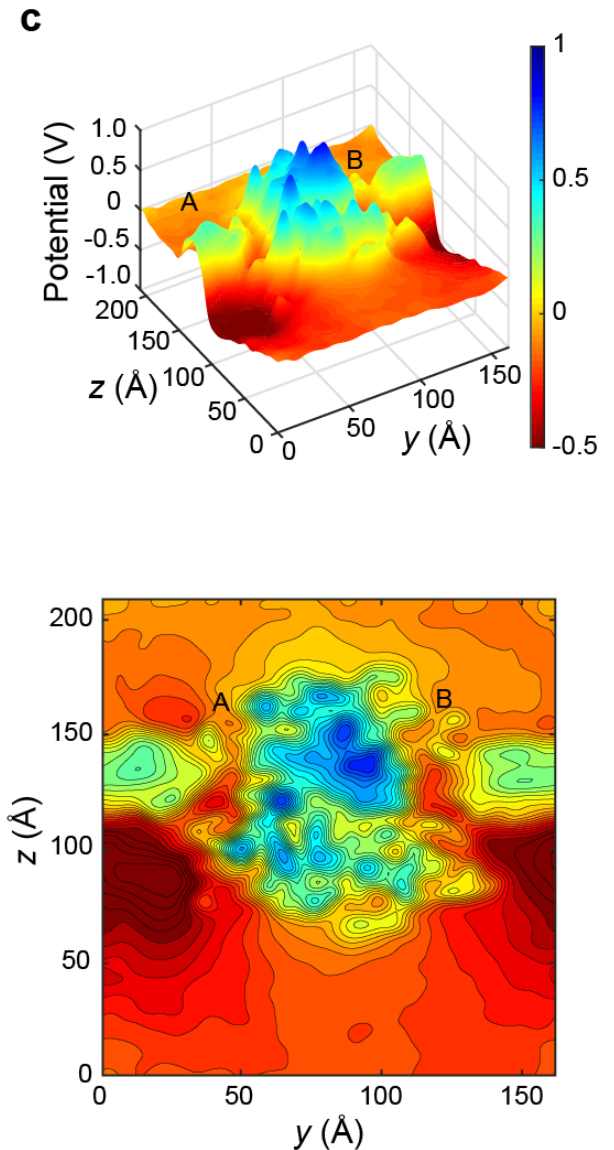

2 Fig. S2 Electrostatic potential surface for the full-length TMC1 system. a-c Cross-section slice through TMC1 3 transmembrane pores showing the averaged electrostatic potential surface (top) and its two-dimensional contour plot for 4 full length TMC1 a at $-0.500 \mathrm{~V}(80 \mathrm{~ns} ; \operatorname{Sim} 1 \mathrm{c})$, b at $-0.250 \mathrm{~V}(250 \mathrm{~ns} ; \operatorname{Sim} 1 \mathrm{~d})$, and c at $-0.125 \mathrm{~V}(100 \mathrm{~ns} ; \operatorname{Sim} 1 \mathrm{f})$. 
a
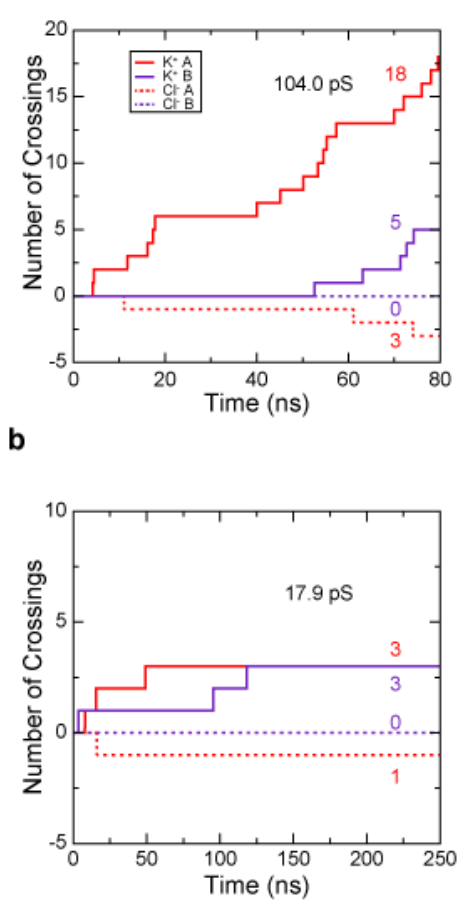

c

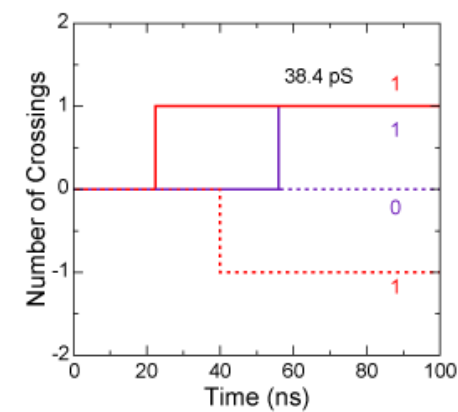

b

d

e

f
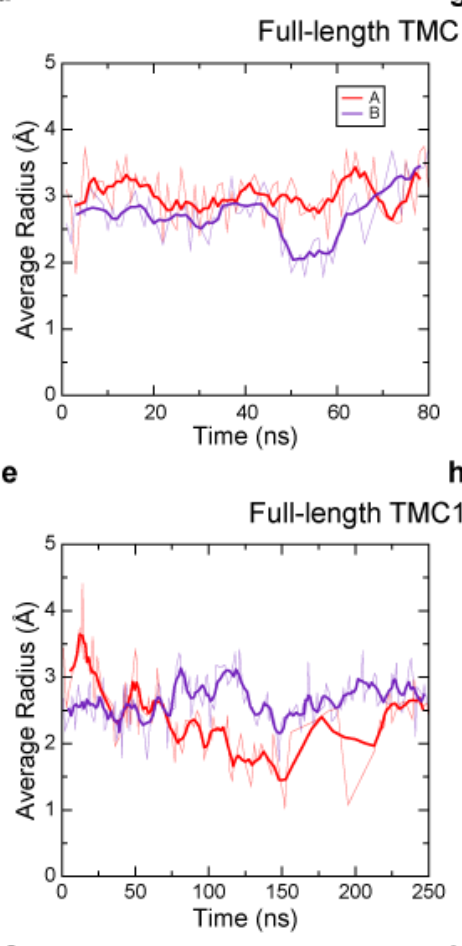

g

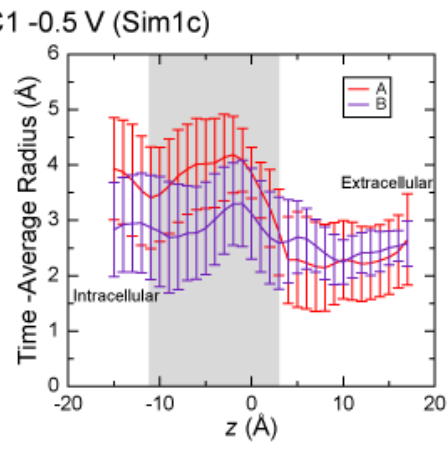

h

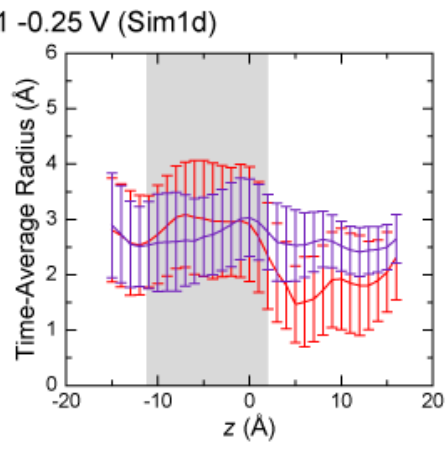

i

Full-length TMC1 -0.125 V ramped-down (Sim1f)

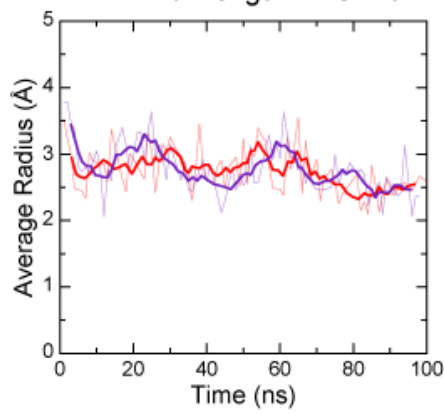

j

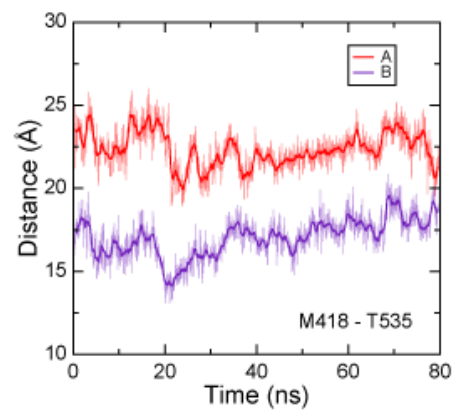

k

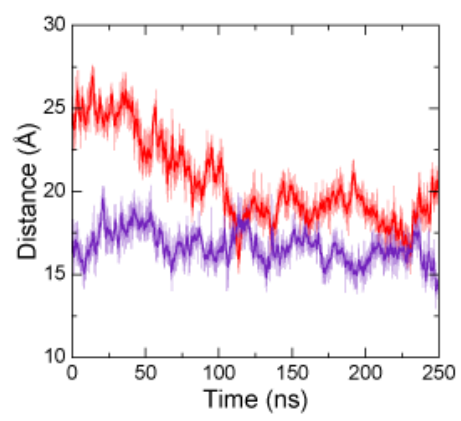

I

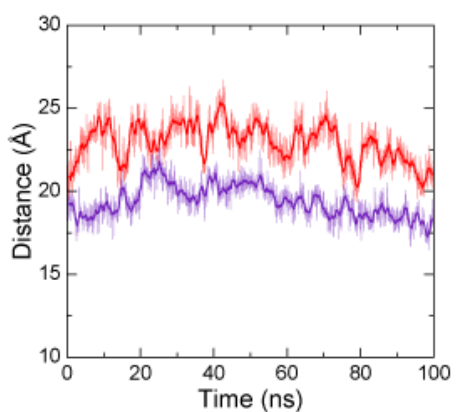

Fig. S3 Ion conduction and pore properties of TMC1. a-c Number of ion crossings as a function of time for full-length TMC1 simulated at a $-0.500 \mathrm{~V}(\mathrm{Sim} 1 \mathrm{c}), \mathbf{b}-0.250 \mathrm{~V}$ (Sim 1d), and $\mathbf{c}-0.125 \mathrm{~V}$ (Sim 1f). Solid lines are for potassium ions going through monomers A (red) and B (indigo). Dashed lines are for chloride ions going through monomers A (red) and $\mathrm{B}$ (indigo). d-f Average radius across the pore axis $(z)$ for each monomer as a function of time for TMC1 simulated at $\mathbf{d}$ $0.500 \mathrm{~V}$ (Sim 1c), e at $-0.250 \mathrm{~V}$ (Sim1d), and $\mathbf{f}$ at $-0.125 \mathrm{~V}$ (Sim1f). Transparent lines show raw data after curation (see Methods) while solid lines indicate their 5-ns running averages. g-i Time-averaged radii as a function of position $(z)$ along the pore axis for TMC1 simulated at $\mathbf{g}-0.500 \mathrm{~V}$ (Sim1c), h $-0.250 \mathrm{~V}$ (Sim1d), and $\mathbf{i}-0.125 \mathrm{~V}$ (Sim 1f). Value of $z$ increases from intra- to extra-cellular sides. Error bars are standard deviation. $\mathbf{j}-\mathbf{l}$ Separation between $\mathrm{C}_{\alpha}$ atoms of $\mathrm{Met}^{418}$ in $\alpha 4$ and $\mathrm{Thr}^{535}$ in $\alpha 6$ as a function of time for TMC1 simulated at $\mathbf{j}-0.500 \mathrm{~V}$ (Sim1 c), $\mathbf{k}$ at $-0.250 \mathrm{~V}$ (Sim1d), and $\mathbf{l}-0.125 \mathrm{~V}$ (Sim1f). Transparent lines indicate raw data recorded every $50 \mathrm{ps,} \mathrm{solid} \mathrm{lines} \mathrm{are} 1$ ns running averages. 


\section{a}

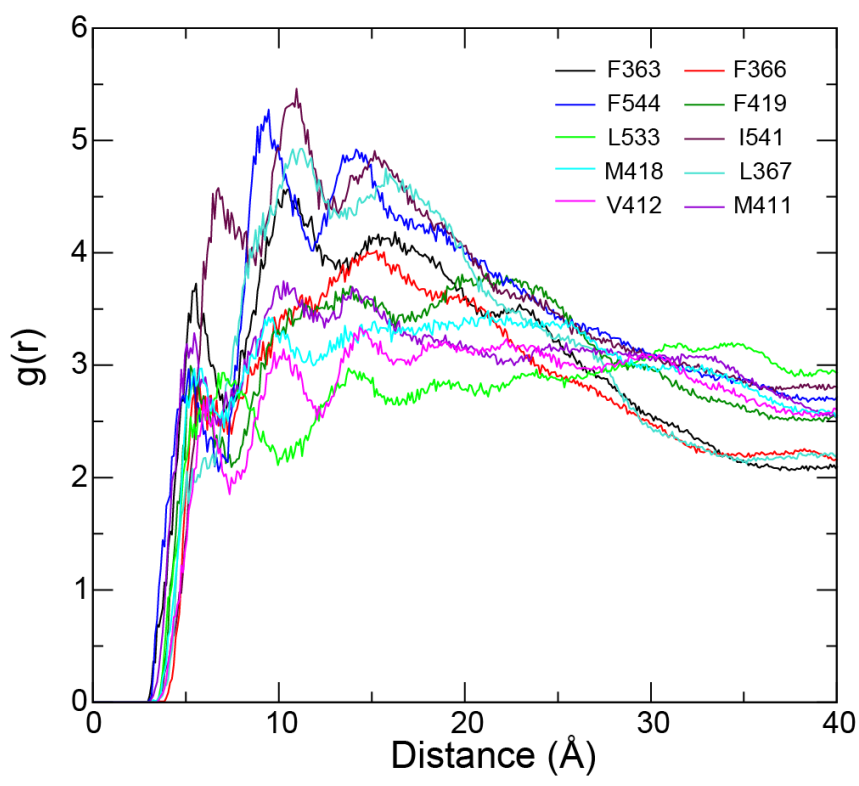

C

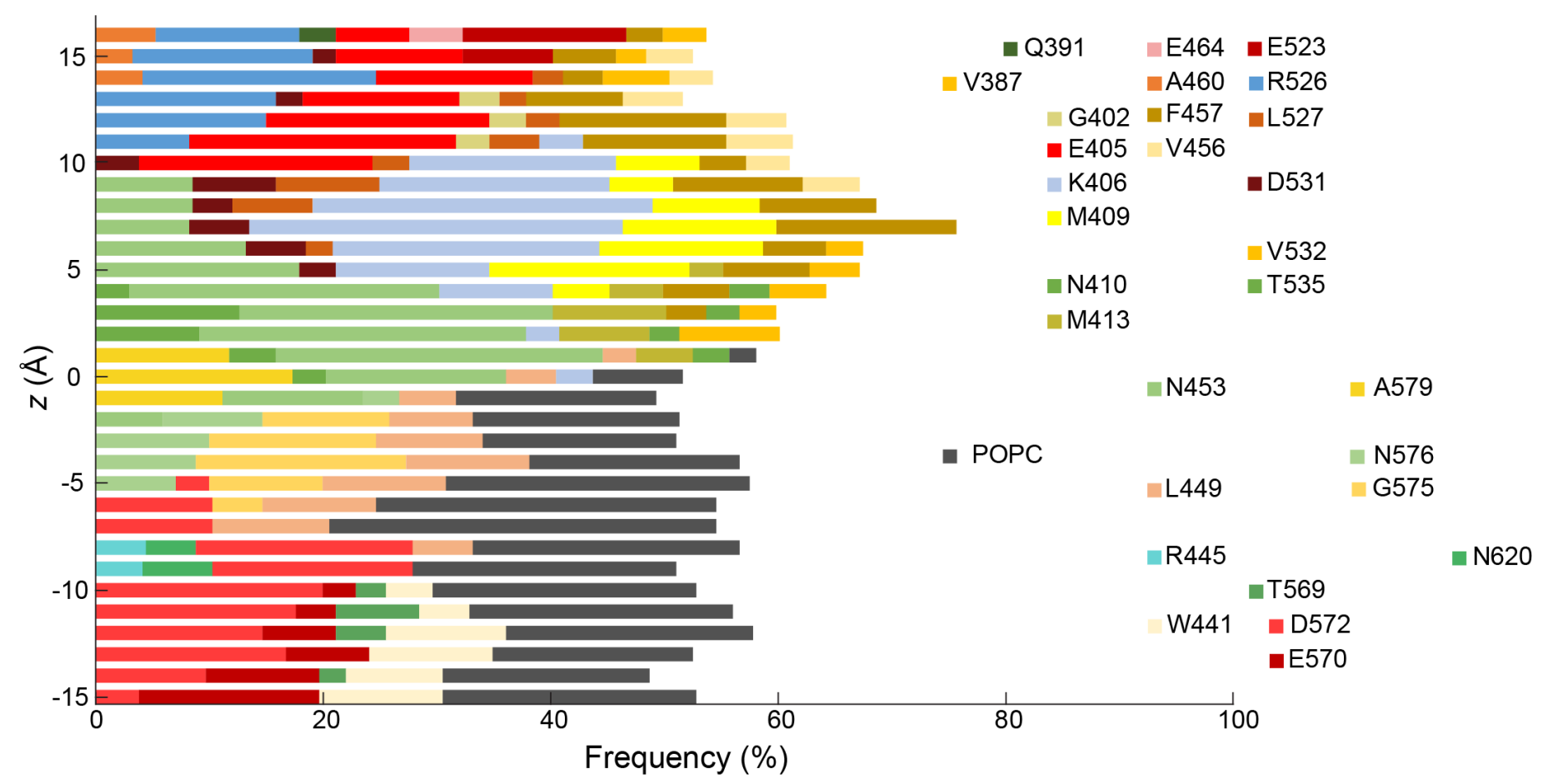

b

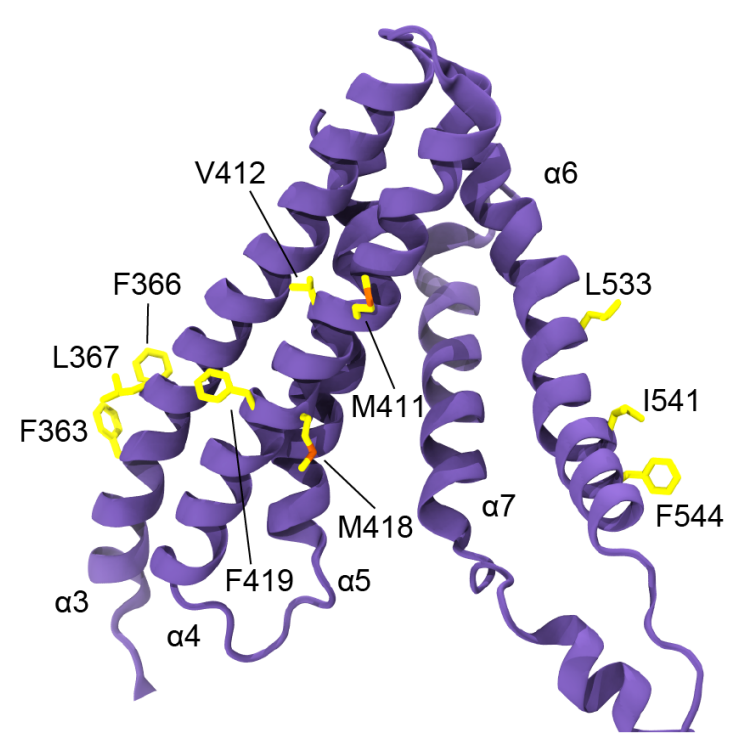

Fig. S4 Membrane-interacting and pore-lining residues. a Radial distribution function $g(r)$ for lipid tails as a function of distance from $\mathrm{C}_{\alpha}$ atoms of key hydrophobic residues in monomer A during a simulation of TMC1 at $-0.500 \mathrm{~V}$ (Sim1c). Top 10 residues were selected after computing $g(r)$ for hydrophobic residues in helices $\alpha 3$ to $\alpha 7$ during Sim $1 \mathrm{c}$ and computing the highest area under the curve between 0 to $6 \AA$. b TMC 1 transmembrane helices $\alpha 3$ to $\alpha 7$ showing the location of residues listed in a. $\mathbf{c}$ Key residues that line the hydrophilic pore as a function of distance $z$ along the pore axis during simulations of full-length TMC1 with transmembrane potential (Sim1d-Sim1f). To determine the frequency at which residues appeared to line the pore we analyzed the HOLE output and identified the three residues that lined the pore most often at each value of $z$ along the axis in each of the simulations. 
a

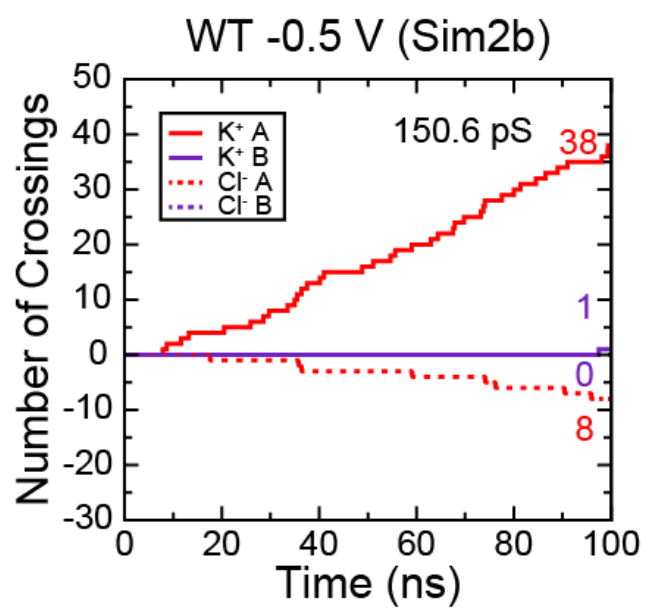

d

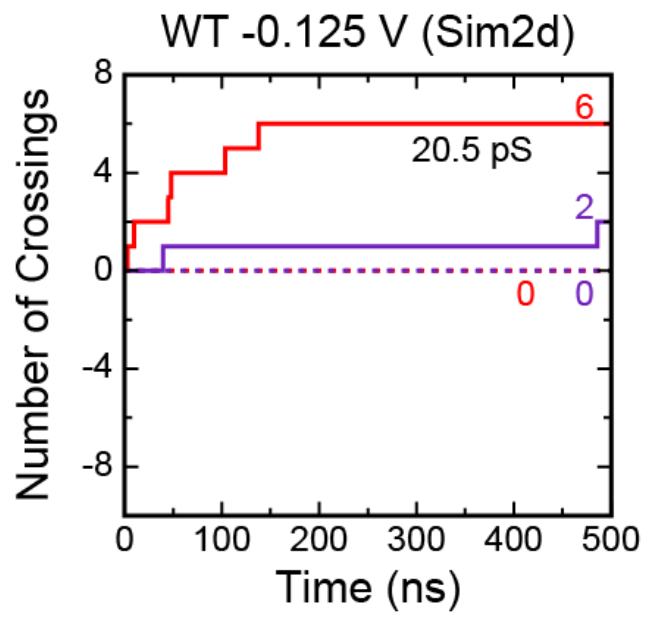

b
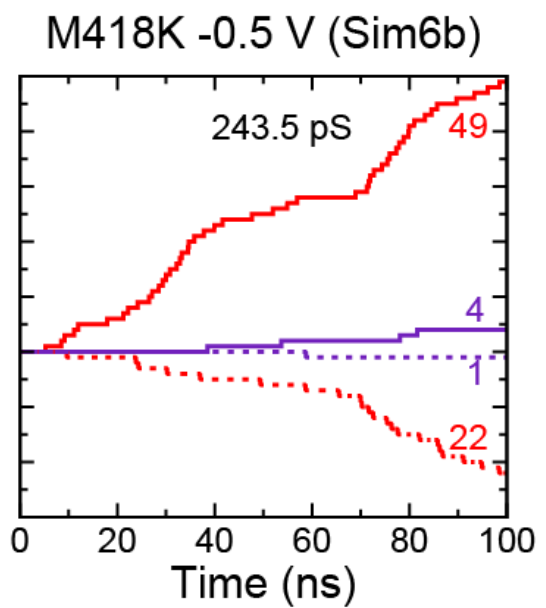

e
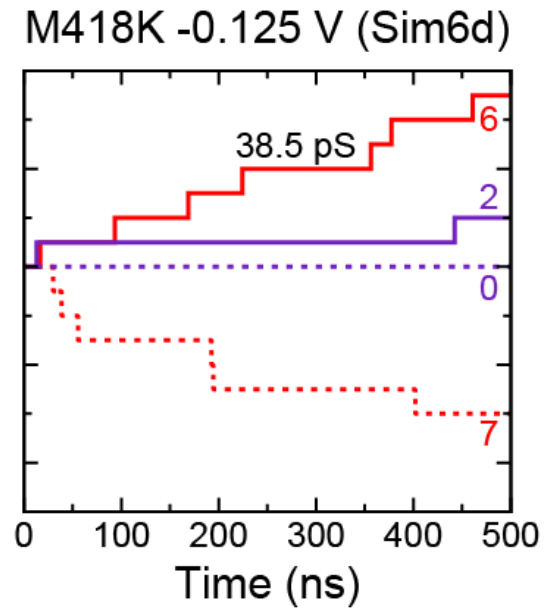

C

D572N -0.5 V (Sim7b)

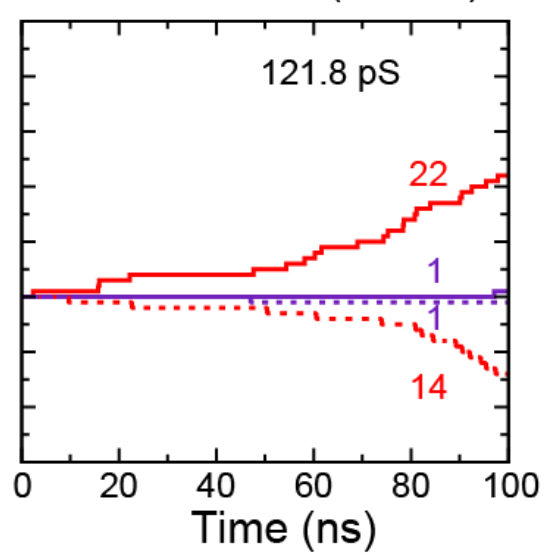

$f$

D572N $-0.125 \vee(\operatorname{Sim} 7 d)$

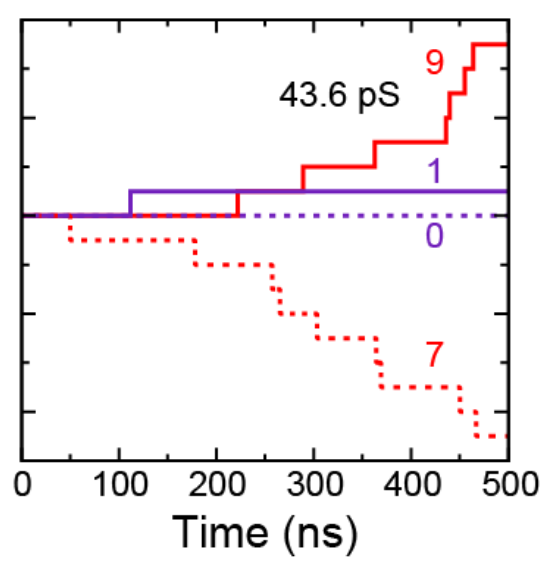

Fig. S5 Ion conduction through a minimalistic truncated model of the TMC1 dimer. a-c Number of ion crossings through the pore of the wild type, M418K, and D572N truncated TMC1 systems at $-0.500 \mathrm{~V}$ (Sim2b, Sim6b, and Sim7b). Solid and dashed lines denote potassium and chloride permeation events, respectively. d-f Ion crossing events through the pore of the wild type, M418K, and D572N truncated TMC1 systems at $-0.125 \mathrm{~V}$ (Sim2d, Sim6d, and Sim7d). Solid and dashed lines denote potassium and chloride permeation events, respectively. Panels a,d are also shown in Fig. S7a,c. 
a

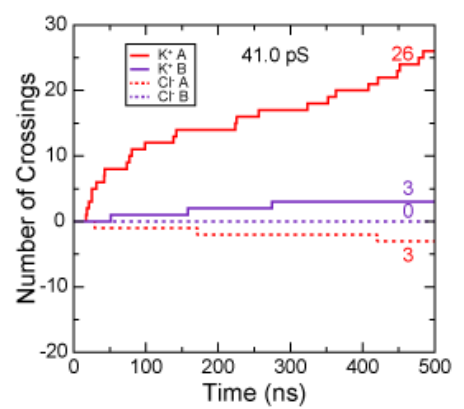

b

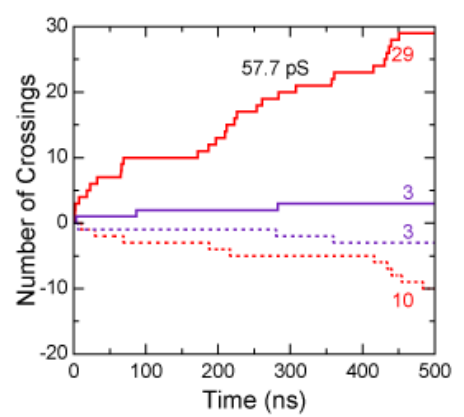

c

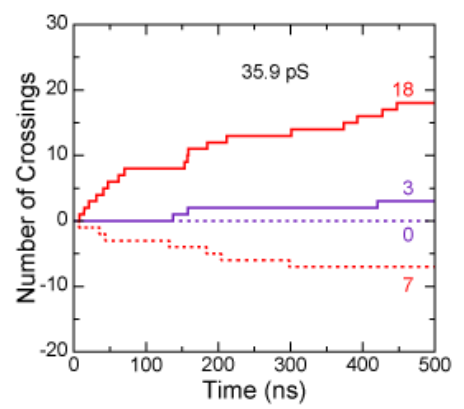

d

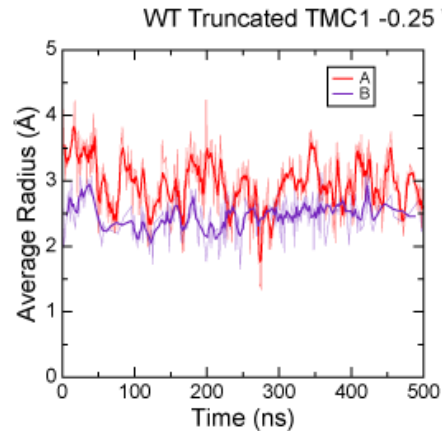

e

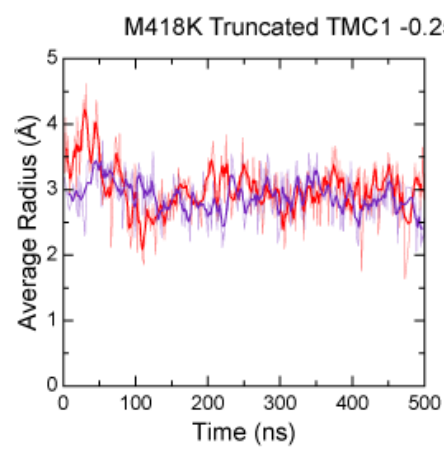

f

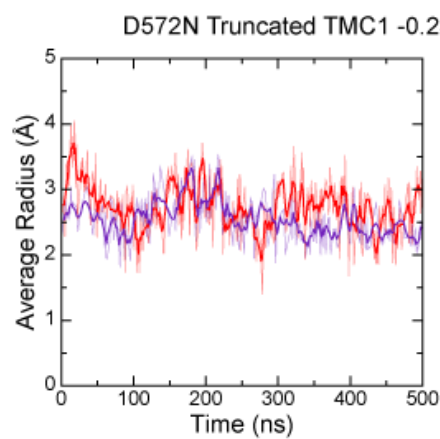

g

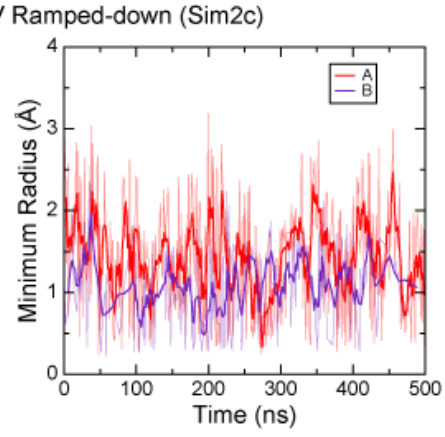

h

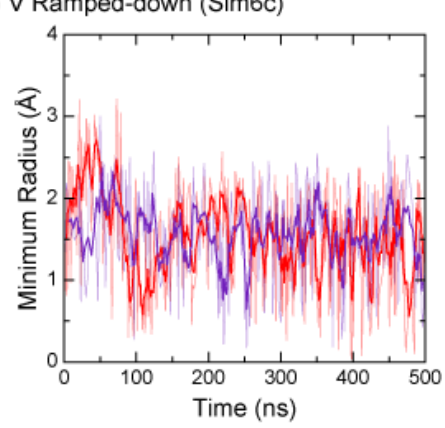

i

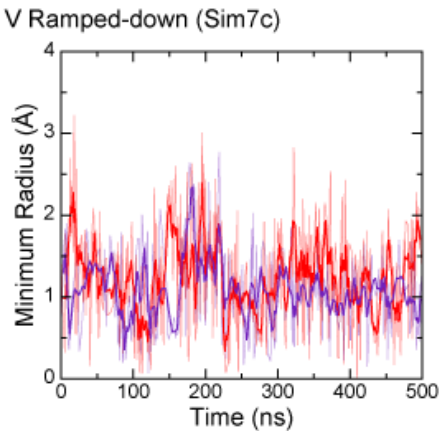

j

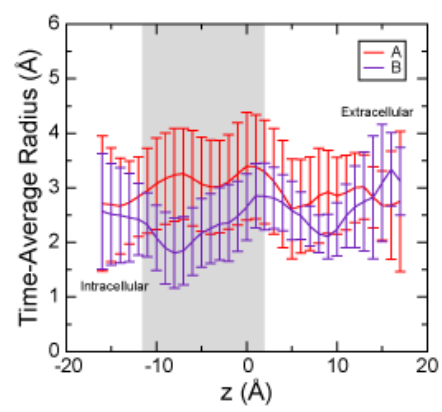

k

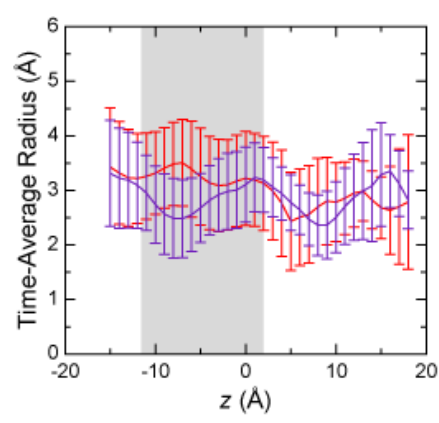

I

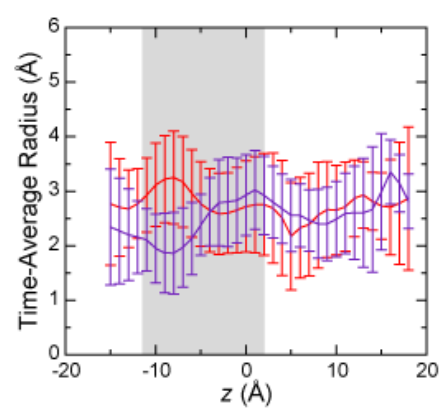

Fig. S6 Ion conduction and pore properties of truncated TMC1 systems. a-c Number of ion crossings as a function of time for truncated TMC1 systems at $-0.250 \mathrm{~V}$ including a wild-type protein (Sim2c; also shown in Fig. 3d), b M418K mutant (Sim6c), and c D572N mutant (Sim7c). Shown as in Fig. S3a-c. d-f Average radius across the pore axis $(z)$ for each monomer as a function of time for truncated TMC1 systems at $-0.250 \mathrm{~V}$ including $\mathbf{d}$ wild-type protein (Sim2c), e M418K mutant (Sim6c), and $\mathbf{f}$ D572N mutant (Sim7c). Shown as in Fig S3d-f. g-i Minimum radii of each monomer pore as a function of time for truncated TMC1 systems at $-0.250 \mathrm{~V}$ including $\mathbf{g}$ wild-type protein (Sim2c), $\mathbf{h}$ M418K mutant (Sim6c), and $\mathbf{i}$ D572N mutant (Sim7c). j-l Time-averaged radii as a function of position $(z)$ along the pore axis for truncated TMC1 systems at $-0.250 \mathrm{~V}$ including $\mathbf{j}$ wild-type protein (Sim2c), $\mathbf{k}$ M418K mutant (Sim6c), and $\mathbf{l}$ D572N mutant (Sim7c). Shown as in Fig S3g-i. Panels a,d,g,j are also shown in Fig. S7b,e,h,k. 
bioRxiv preprint doi: https://doi.org/10.1101/2021.09.17.460860; this version posted September 18, 2021. The copyright holder for this preprint (which was not certified by peer review) is the author/funder, who has granted bioRxiv a license to display the preprint in perpetuity. It is made available under aCC-BY-NC-ND 4.0 International license.

a

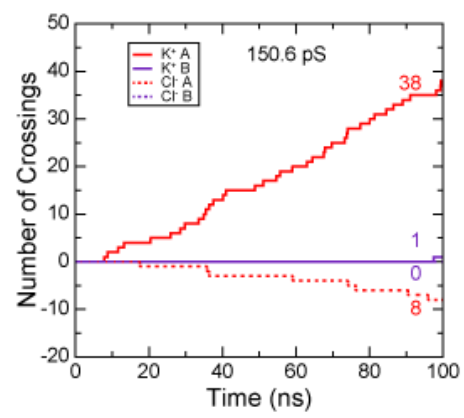

b

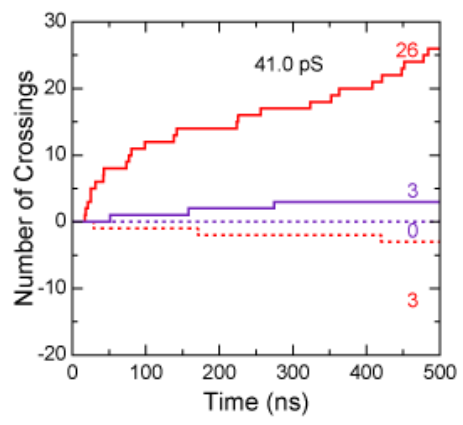

C

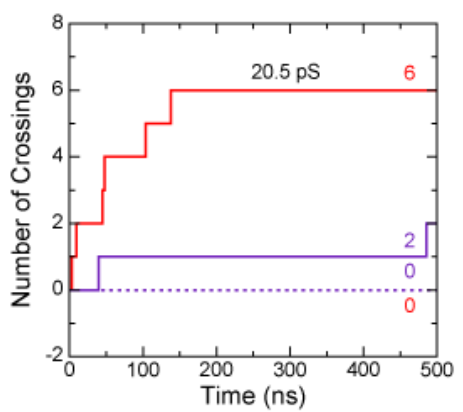

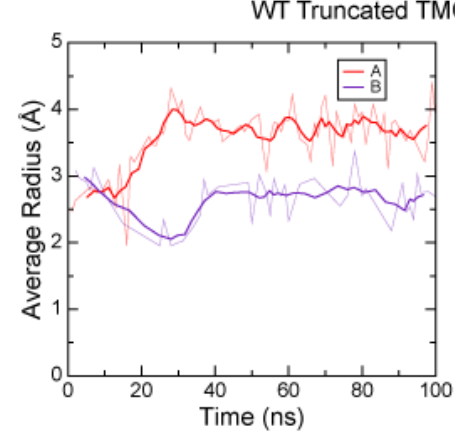

e

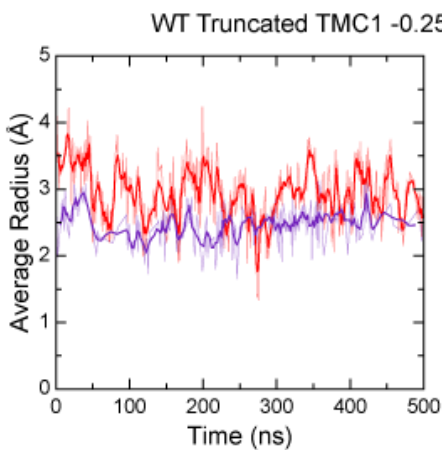

f

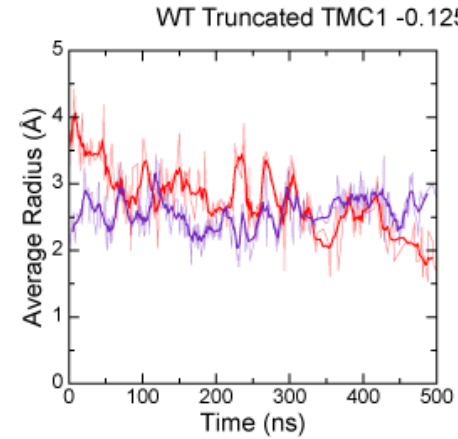

g

$1-0.5 \mathrm{~V}$ (Sim2b)

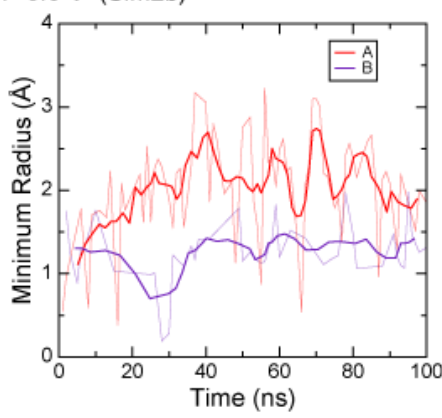

h

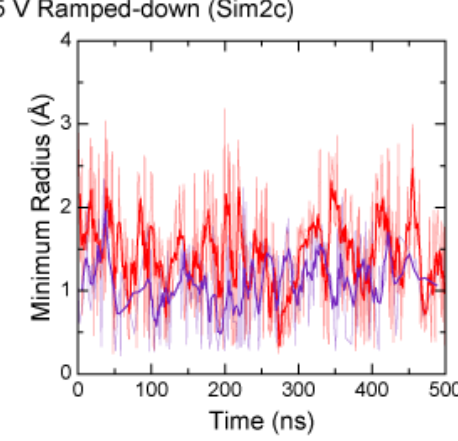

i

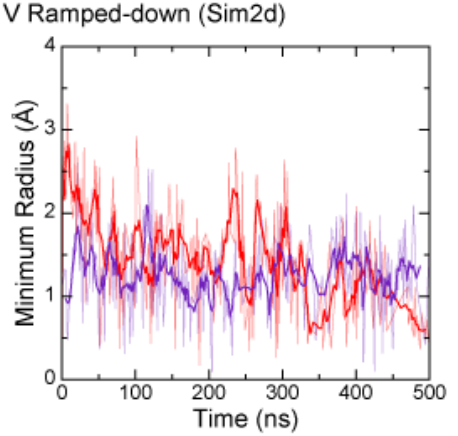

j

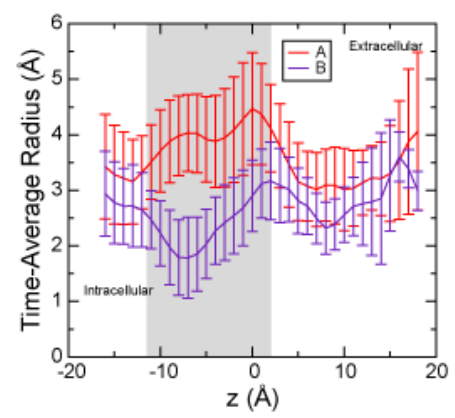

k

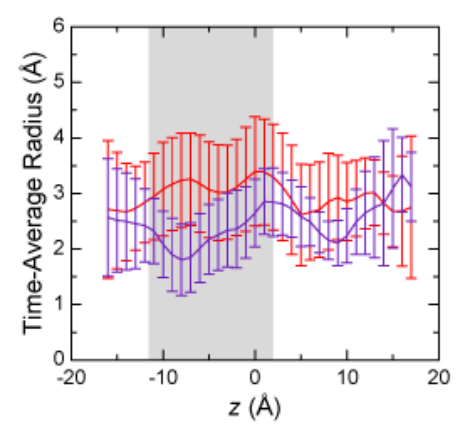

I

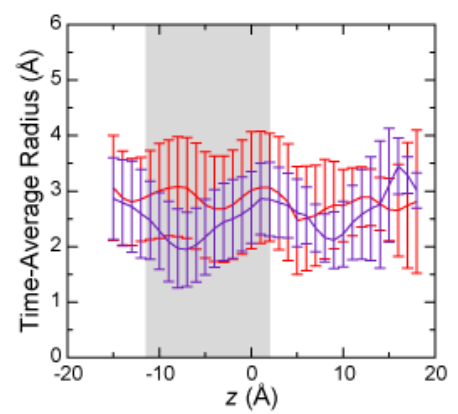

Fig. S7 Ion conduction and pore properties of the wild-type truncated TMC1 system. a-c Number of ion crossings as a function of time for a wild-type truncated TMC1 system at a $-0.500 \mathrm{~V}(\operatorname{Sim} 2 \mathrm{~b}), \mathbf{b}-0.250 \mathrm{~V}(\operatorname{Sim} 2 \mathrm{c})$, and $\mathbf{c}-0.125 \mathrm{~V}$ (Sim2d). Shown as in Fig. S3a-c. d-f Average radius across the pore axis $(z)$ for each monomer as a function of time for a wild-type truncated TMC1 system at $\mathbf{d}-0.500 \mathrm{~V}(\operatorname{Sim} 2 \mathrm{~b}), \mathbf{e}-0.250 \mathrm{~V}$ (Sim2c), and f $-0.125 \mathrm{~V}$ (Sim2d). Shown as in Fig S3 d-f. g-i Minimum radii of each monomer pore as a function of time for a wild-type truncated TMC1 system at $\mathbf{g}-0.500$ V (Sim $2 b), \mathbf{h}-0.250 \mathrm{~V}(\operatorname{Sim} 2 \mathrm{c})$, and $\mathbf{i}-0.125 \mathrm{~V}(\operatorname{Sim} 2 \mathrm{~d})$. $\mathbf{j}-\mathbf{l}$ Time-averaged radii as a function of position $(z)$ along the pore axis for a wild-type truncated TMC1 system at $\mathbf{j}-0.500 \mathrm{~V}(\operatorname{Sim} 2 \mathrm{~b}), \mathbf{k}-0.250 \mathrm{~V}(\operatorname{Sim} 2 \mathrm{c})$, and $\mathbf{l}-0.125 \mathrm{~V}(\operatorname{Sim} 2 \mathrm{~d})$. Shown as in Fig S3g-i. Panels b,e,h,k are also shown in Fig. S6a,d,g,j. Panels a,c are also shown in Fig. S5a,d. 
bioRxiv preprint doi: https://doi.org/10.1101/2021.09.17.460860; this version posted September 18, 2021. The copyright holder for this preprint (which was not certified by peer review) is the author/funder, who has granted bioRxiv a license to display the preprint in perpetuity. It is made available under aCC-BY-NC-ND 4.0 International license.

a
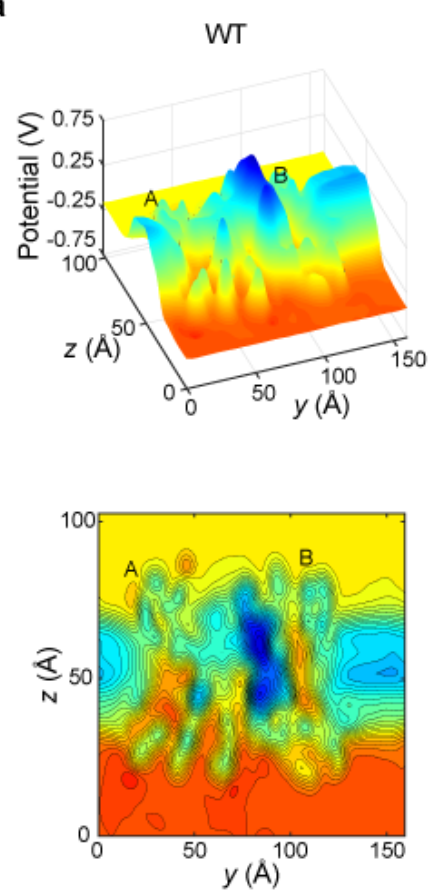

e

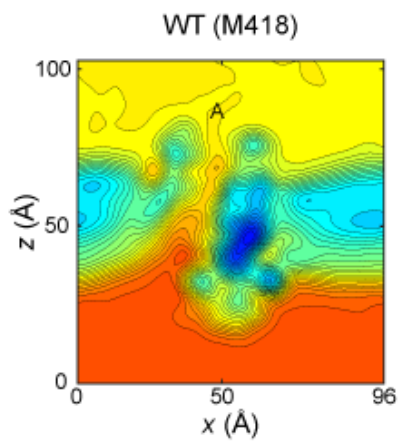

b

M418K
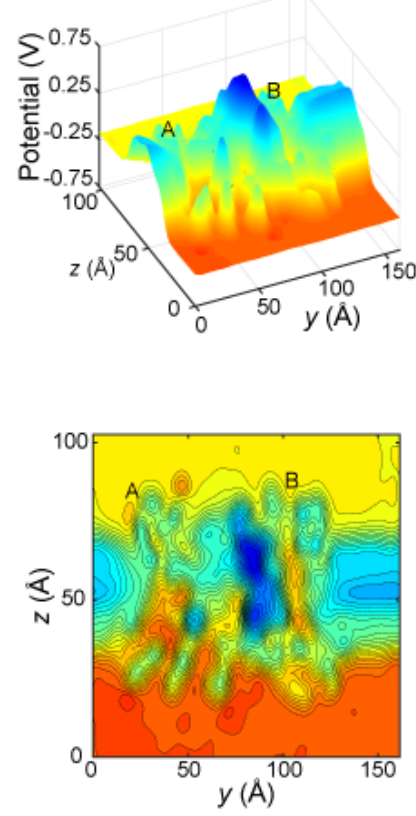

f

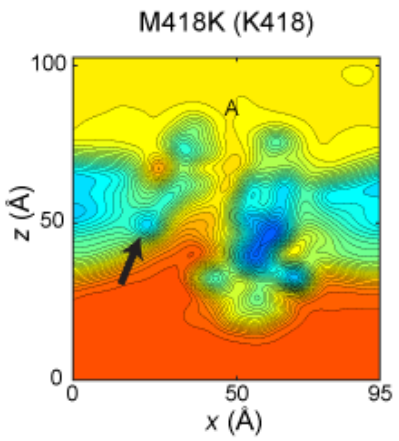

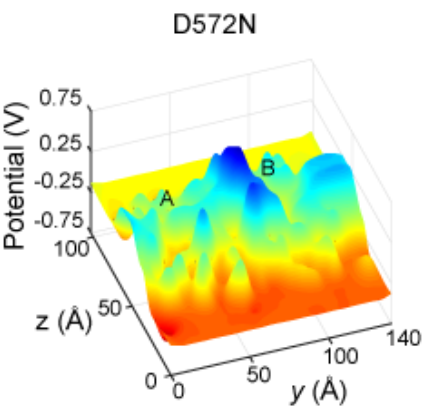

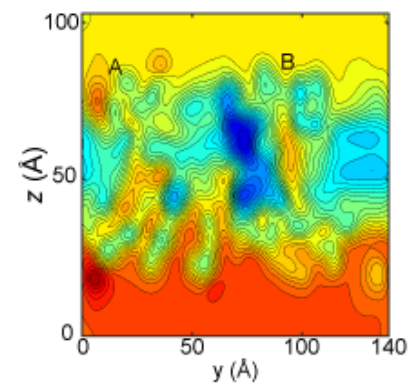

g

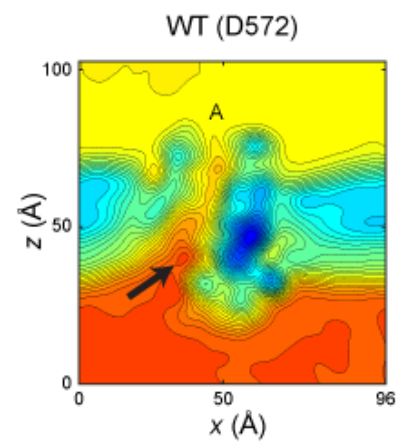

d
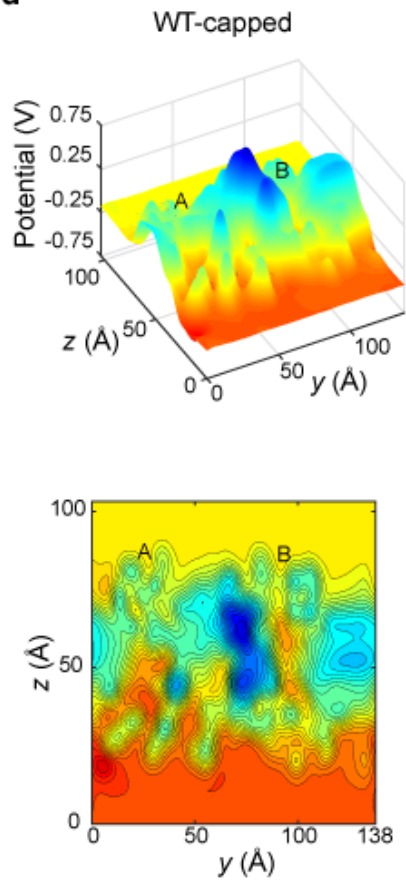

h

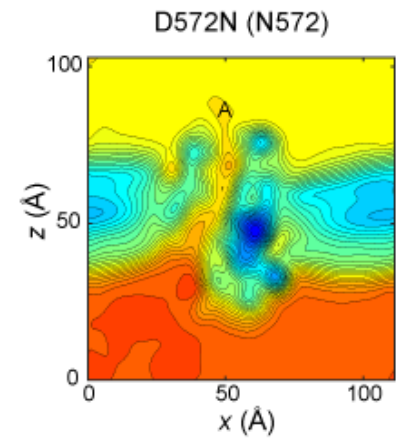

Color

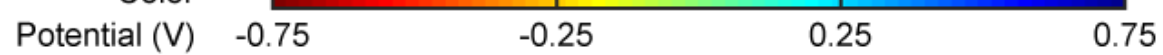

Fig. S8 Electrostatic potential surface for truncated TMC1 systems. a-d Cross-section slice through TMC1 transmembrane pores showing the averaged electrostatic potential surface (top) and a its two-dimensional contour plot at $0.250 \mathrm{~V}$ for the a wild-type protein (Sim2c), b M418K mutant (Sim6c), c D572N (Sim7c), and d wild-type capped protein (Sim8c). e-h Two-dimensional contour plot of a monomer A cross-section slices of the averaged electrostatic potential at $0.250 \mathrm{~V}$ for e wild-type protein (plane passing through M418; Sim2c), f M418K mutant (plane passing through K418; Sim6c), g wild-type protein (plane passing through D572; Sim2c), and h D572N mutant (plane passing through N572;

$8 \quad \operatorname{Sim} 7 \mathrm{c})$. Black arrows indicate changes in electrostatic potential near the mutated residues. 
bioRxiv preprint doi: https://doi.org/10.1101/2021.09.17.460860; this version posted September 18, 2021. The copyright holder for this preprint (which was not certified by peer review) is the author/funder, who has granted bioRxiv a license to display the preprint in perpetuity. It is made available under aCC-BY-NC-ND 4.0 International license.

Table S1 - Control simulations of KCl bulk electrolyte

\begin{tabular}{ccccccccc}
\hline Label & Length (ns) & Voltage & $\mathbf{K}_{+\mathbf{z}}^{+}$ & $\mathbf{K}_{-\mathbf{z}}^{+}$ & $\mathbf{C I}_{+\mathbf{z}}^{+}$ & $\mathbf{C l}_{-\mathbf{z}}^{-}$ & $\mathbf{I ~} \mathbf{~ A}$ & $\mathbf{C}(\mathbf{p S})$ \\
\hline Sim9a & 10 & 0 & - & - & - & - & - & - \\
Sim9b & 10 & 0 & - & - & - & - & - & - \\
Sim9c & 10 & -0.500 & 11 & 589 & 558 & 17 & 17.93 & 35.85 \\
Sim9d & 10 & -0.500 & 11 & 569 & 599 & 12 & 18.34 & 36.69 \\
Sim9e & 10 & -0.250 & 58 & 335 & 334 & 50 & 8.99 & 35.95 \\
Sim9f & 10 & -0.250 & 58 & 346 & 329 & 56 & 8.99 & 35.95 \\
Sim9g & 10 & -0.125 & 90 & 243 & 240 & 92 & 4.82 & 38.58 \\
Sim9h & 10 & -0.125 & 97 & 231 & 242 & 110 & 4.26 & 34.09 \\
\hline
\end{tabular}

